\title{
Cambios en la sociedad Lima ReFlejados EN LA arquitectura del Centro Ceremonial de Pucllana DURANTE LAS PRIMERAS ÉPOCAS DEL HORIZONTE MEDIO: Las eVidencias de la Plataforma IV
}

\author{
Nilton Ríos P.* \\ José Ccencho Huamani***
}

\begin{abstract}
Resumen
Las últimas investigaciones realizadas en la Plataforma IV del Centro Ceremonial ${ }^{1}$ de Pucllana, demostraron una secuencia arquitectónica correspondiente a la época 1A del Horizonte Medio. Tales evidencias se encontraron superpuestas por arquitectura correspondiente a la siguiente época 1B, registrándose cambios significativos en la conformación de los espacios en las etapas constructivas definidas. La fragmentería recuperada de estilo Nievería se asoció al desarrollo arquitectónico de dicha plataforma en sus fases tardías, estos también manifestaron notorias innovaciones en la decoración, lo cual indicaría también cambios a nivel ideológico-político en la cultura Lima. Las evidencias demuestran que hubo una ocupación permanente en el Centro Urbano de Pucllana durante las dos primeras épocas del Horizonte Medio. Asimismo, la secuencia arquitectónica en su etapa tardía se caracterizó por la pérdida del carácter ceremonial y la conformación de espacios de características más seculares.
\end{abstract}

Palabras Clave

Huaca Pucllana, Horizonte Medio 1A, etapas constructivas, transformaciones sociales, pérdida del carácter ceremonial.

\begin{abstract}
Latest researches made in Platform IV of the Ceremonial Center of Pucllana, demonstrated an architectonic sequence corresponding to the time $1 \mathrm{~A}$ of the Middle Horizon. Such evidences were superposed by architecture corresponding to the following time $1 \mathrm{~B}$, register significant changes in the configuration of the spaces in the defined constructive stages. Recovered Nievería style sherds were associated to the architectonic development of this platform in its delayed phases, these pieces also indicated eminent innovations in the decoration, showing also changes at ideological-political level in the Lima culture. The evidences reveal that there was a permanent occupation in the Urban Center of Pucllana during the two first times of the Middle Horizon. Also, the architectonic sequence in its delayed stage was characterized by the loss of the ceremonial features and the arrangement of spaces of more secular patterns.
\end{abstract}

Keywords

Huaca Pucllana, Middle Horizon 1A, Constructive stages, Social transformations, Loss of the ceremonial character.

* Proyecto Arqueológico Huaca Pucllana, Licenciado en Arqueología.

Correo electrónico: paliveomo@hotmail.com

** Proyecto Arqueológico Huaca Pucllana, Licenciado en Arqueología.

Correo electrónico: joseccenchoh@hotmail.com

1 Aunque conferirle connotaciones especiales de ceremonialidad a un sólo componente arquitectónico puede resultar un poco controversial o una invitación al debate teórico con respecto a qué se le está denominando ceremonial y qué no lo es. Dado que, muchos eventos de fuertes connotaciones rituales también se han realizado en otros 


\section{INTRODUCCIÓN}

El presente trabajo es resultado de las excavaciones realizadas en la Plataforma IV del Centro Ceremonial de Pucllana, estas se realizaron como parte de las investigaciones del Proyecto Arqueológico Huaca Pucllana -temporadas 2005-2006-, dirigida por la doctora Isabel Flores. El cual se ejecuta bajo el convenio entre el Instituto Nacional de Cultura y la Municipalidad de Miraflores. Dichas excavaciones se concentraron en dos flancos (ladera norte y este).

Antes de iniciarse las excavaciones, se sabía que dicha plataforma en su fase tardía se conformó de dos componentes arquitectónicos -una plaza pintada de amarillo y una pequeña plataforma rectangular,- estos habían sido excavados en anteriores temporadas definiéndose un piso que sellaba ambos componentes del cual había quedado una pequeña área en la parte central. Similares trabajos fueron desarrollados anteriormente en las Plataformas II y III (fig. 1a y 1b), las cuales demostraron que se habían configurado mediante amplios espacios abiertos a modo de plazas asociados a banquetas y postes, en algunas estructuras se registraron restos de enlucido amarillo, donde al parecer se habrían desarrollado actividades rituales (Flores 2005: 36-38). Sin embargo, en otros centros ceremoniales Lima las evidencias parecen manifestar diferencias en cuanto a la función de las plataformas; dado que, en 1910 Max Uhle explorando el Centro Urbano de Maranga, halló sobre una de las plataformas varios fragmentos decorados correspondientes a 80 vasijas presumiblemente destinadas al aprovisionamiento de chicha o de cereales del centro ceremonial (Uhle 1998: 248). Otras excavaciones como la de Jijón y Caamaño en los montículos I y III (Montículos 15 y 16, 18, 19 del plano de Middendorf) planteó que se habían conformado en tres fases constructivas y seis épocas diferentes. Asimismo, refiere hipotéticamente que la primera fase correspondió a graneros o lugares de culto, mientras que en la Segunda y Tercera Fase fueron definidas como "terrazas" con evidencias de actividades rituales y cementerios de la época Protolima (Caamaño 1949: 483-500). Ese mismo año Alfred L. Kroeber también realizó excavaciones en varios montículos del complejo Maranga, Bajada Balta y recolecciones superficiales en la Huaca Pucllana, llegando a la conclusión que el estilo Protolima correspondía a una etapa anterior a las influencias Tiahuanacoides, mientras que el estilo Nievería probablemente había coexistido con el Protolima en su fase tardía. En 1971 los trabajos de Alarcón demostraron que la Huaca San Marcos se desarrolló por Tres Fases Constructivas diferentes en función, temporalidad y técnica constructiva, donde las estructuras más tempranas se caracterizaron por tener atribuciones ceremoniales, mientras que la segunda fase manifestó una pérdida de tales atributos originales. (Alarcón 1971: 104-105). Asimismo, otras investigaciones han coadyuvado a diferenciar las ocupaciones desarrolladas en los centros ceremoniales, tras la reapertura de las investigaciones en la Huaca San Marcos en el 2000, en la Plataforma II se realizaron una serie de hallazgos entre ellos mates pirograbados y cerámica decorada con los estilos Nievería y Pachacamac, adjudicables hipotéticamente a la época 2 del Horizonte Medio (Narváez 2000: 11). En Pachacamac, los resultados de las investigaciones en el Templo Viejo demostraron una ocupación Lima Temprano y otra Tardía asociada a una plaza de grandes dimensiones, una serie de pasadizos y varios recintos de funciones diferenciadas, algunos de ellos enlucidos con pintura negra sobre fondo rojo o amarillo, en algunos recintos se registraron evidencias de quemas rituales al momento de finalizar una

sectores de Pucllana, por el momento no pretendemos desarrollar en extenso las características o esencia del aspecto ceremonial en Pucllana, solamente se desea realizar una diferencia en términos metodológicos cuando nos referimos a todo el asentamiento de Pucllana (Centro Urbano) o solamente a la pirámide principal (Centro Ceremonial). 


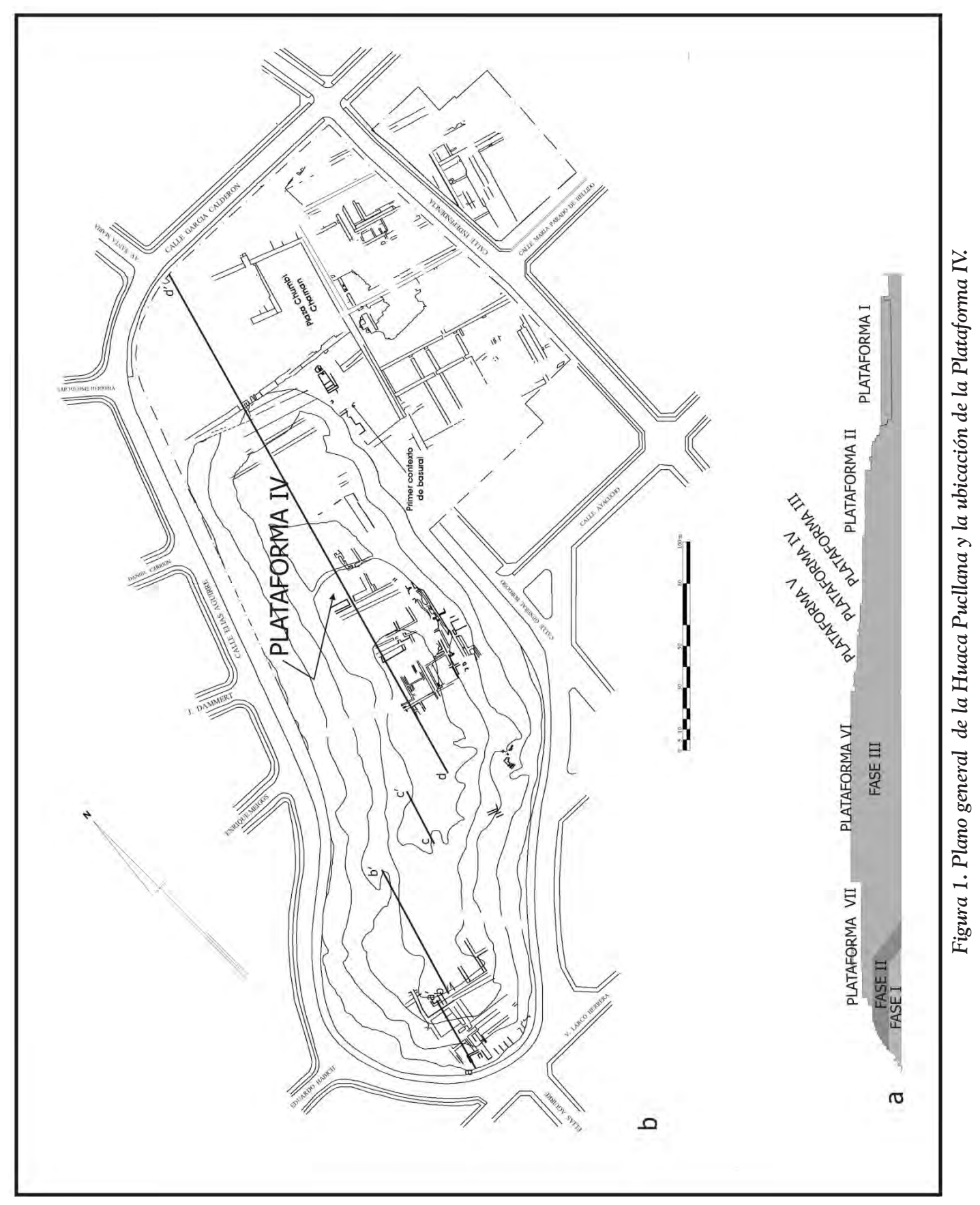






Figura 2. Aspecto general de la Plataforma IV (sector nor-este) antes de las excavaciones.



Figura 3. Unidades Arquitectónicas 1, 2 y 3 de la Primera Etapa Constructiva. (vista nor-este de la Plataforma IV).

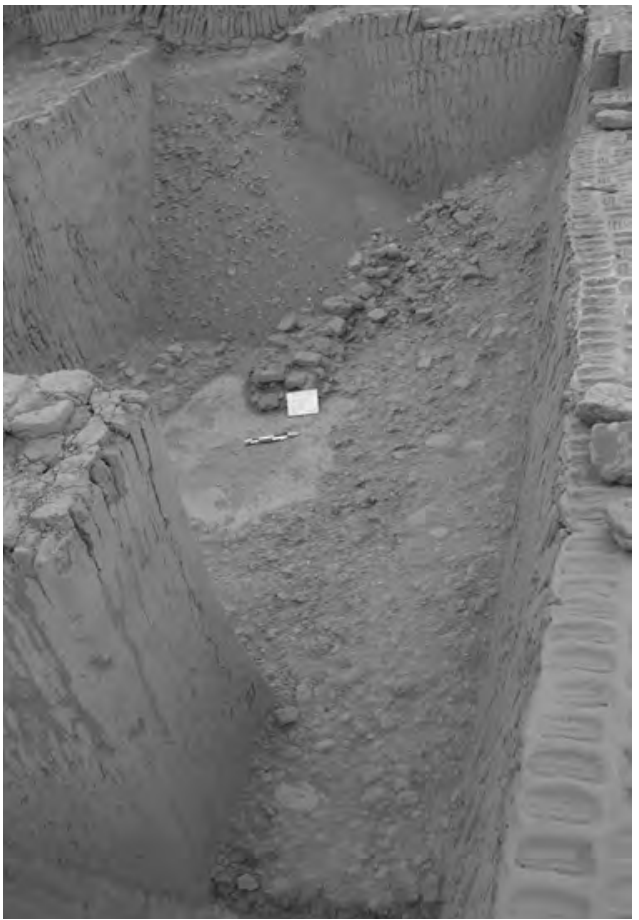

Figura 4. Depósitos de R-A cubriendo la

Unidad Arquitectónica 3, evidencias de eventos destructivos al finalizar la Primera Etapa Constructiva de la Plataforma IV. 


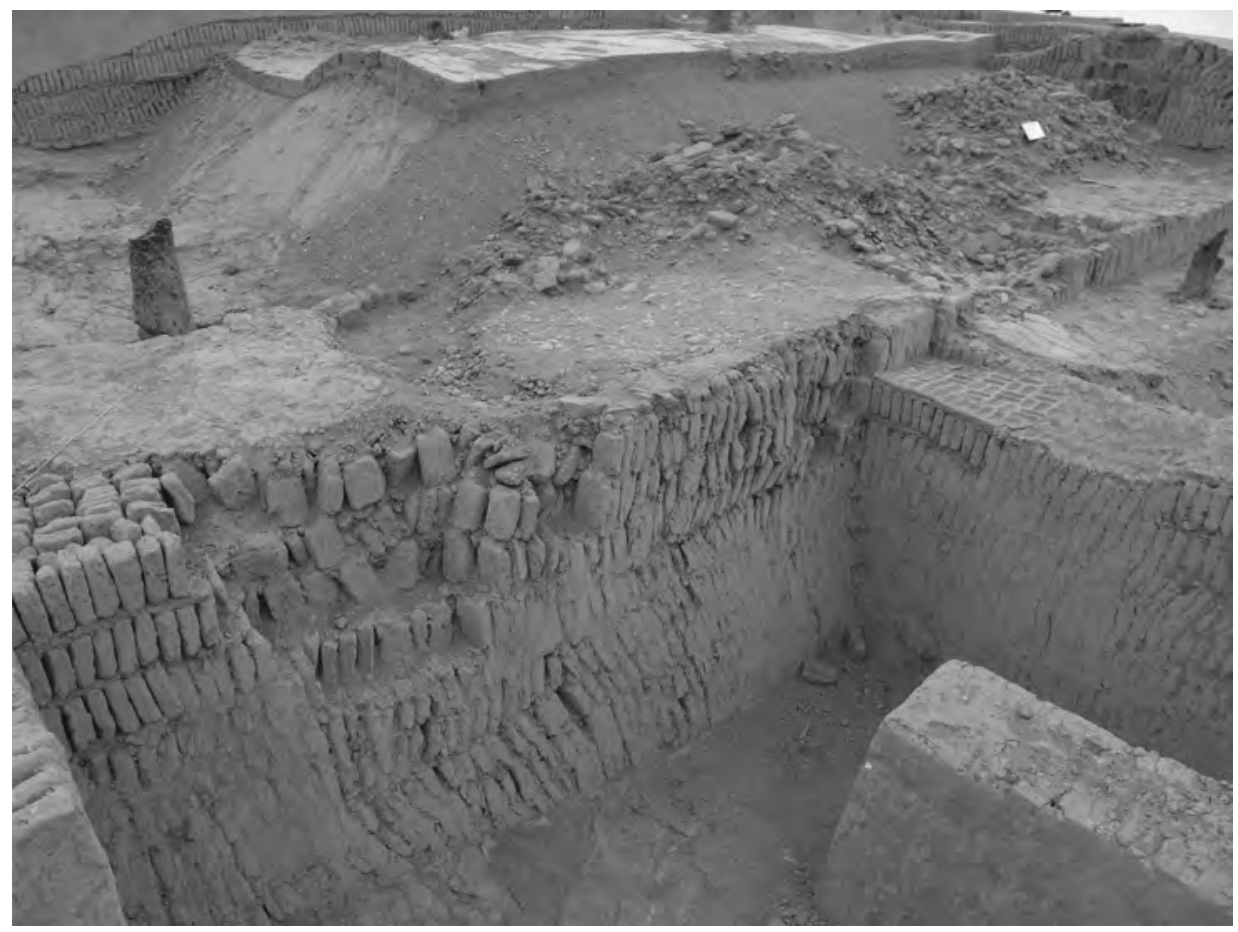

Figura 5. Acumulaciones de adobes fragmentados sobre el piso de la Unidad Arquitectónica 08 (Segunda Etapa Constructiva) de la Plataforma IV.

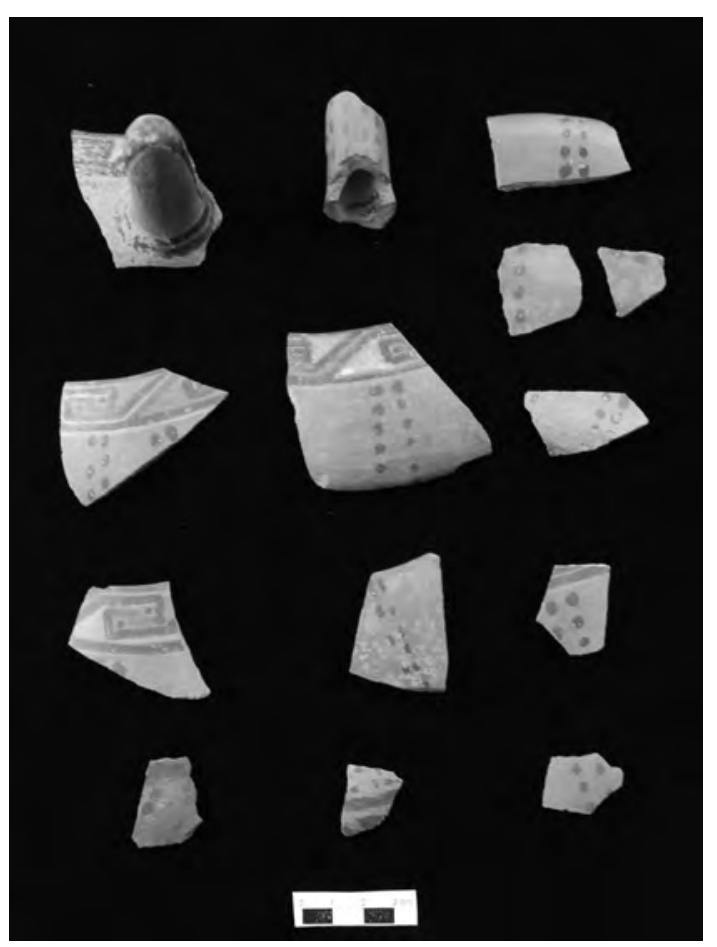

etapa. Mientras que la ocupación del Horizonte Medio se caracterizó por el uso de adobes planos rectangulares y la presencia de enlucido negro y rojo sobre fondo blanco (Franco y Paredes 2003: 162-164).

Es en este marco referencial, donde los datos obtenidos de la Plataforma IV se contrastan para demostrar que el desarrollo arquitectónico del Centro Ceremonial de Pucllana continuó hasta bien ingresado las primeras épocas del Horizonte Medio sin ningún tipo de interrupción. En este sentido, se sostiene que dicha plataforma en sus fases tardías se realizaron cambios significativos en su conformación espacial, que implican también diferencias funcionales y cronológicas en la que fue posible distinguir el tránsito de la época 1A al 1B del Horizonte Medio. Por

Figura 6. Fragmentos de cerámica Nievería Temprano asociados a la Segunda y Tercera Etapa Constructiva de la Plataforma IV. 


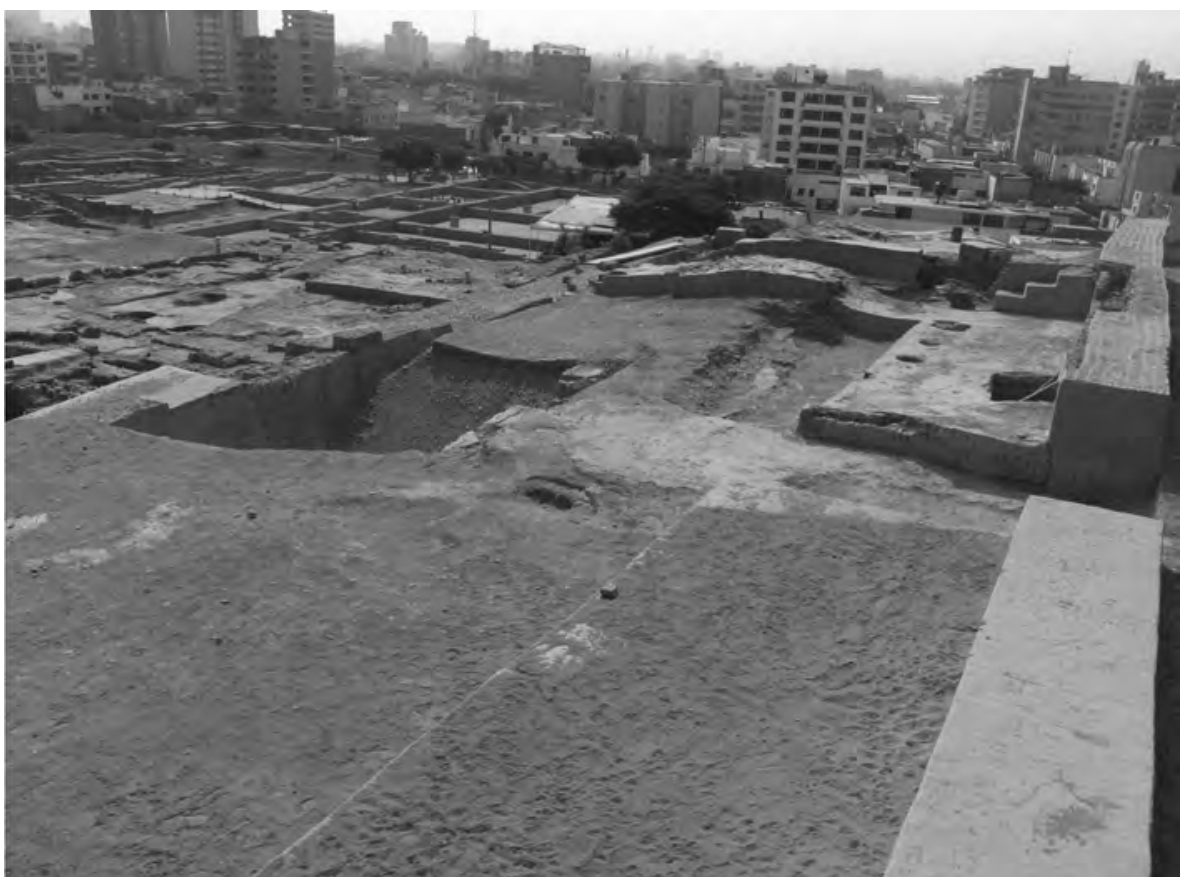

Figura 7. Vista panorámica de la Plaza Amarilla o Unidad Arquitectónica 11, nótese al fondo la plataforma asociada con una escalinata (vista sur-oeste).

lo tanto, uno de nuestros objetivos fue la definición de la secuencia arquitectónica en sus fases tardías de la Plataforma IV y la recuperación de materiales diagnósticos asociados a cada Etapa Constructiva. Lo que nos llevó a plantearnos problemas sobre la arquitectura definida; como la correlación cronológica y las características de la Plataforma IV, cuál fue la funcionalidad de la Plataforma IV durante las primeras épocas del Horizonte Medio, y si existieron diferencias espaciales en el desarrollo arquitectónico.

\section{Aspectos generales de la Plataforma IV}

El Centro Ceremonial de Pucllana en sus últimos momentos constructivos se conformó por siete plataformas (Flores 2005) las que tienen generalmente como largo máximo el eje este - oeste, estas se encuentran orientadas aproximadamente entre 10 y $12^{\circ}$ Noroeste. Cada plataforma se encuentra por lo general delimitada por un pasadizo con una orientación este - oeste (fig. 1a).
La Plataforma IV es la más pequeña de todas (fig. 1b), tiene aproximadamente 11.60 metros de ancho y 47.60 metros de largo, se encuentra delimitada por el norte por un muro de gran altura adosados en varios momentos, en el cual se ubicó un vano de acceso que interconecta a la Plataforma III, y al sur a un pasadizo en sus momentos más tardíos. Además, resalta notoriamente debido que a partir de ella gana altura en conjunto con las demás plataformas ( $\mathrm{V}$ y $\mathrm{VI}$ ) adquiriendo una aspecto majestuoso (fig. 1b). Antes de las intervenciones se comprobó a grandes rasgos que se había conformado de dos espacios arquitectónicos: al oeste, una plaza pequeña con banquetas pintadas de amarillo, que se encontraron parcialmente selladas por rellenos y un piso; y el segundo espacio al este, por un recinto rectangular (pequeña plataforma) asociado a una serie de hoyos de postes en superficie, gran parte de este recinto se encontró cubierto por depósitos de rellenos 
mezclados (fig. 2), resultado de las erosiones y deslizamientos de las laderas norte y este de la plataforma.

\section{LA DEFINICIÓN DE LAS UNIDADES ARQUITECTÓNICAS}

\section{Unidad Arquitectónica 01}

Recinto rectangular de $3.30 \mathrm{~m}$ de largo y 2.30 $\mathrm{m}$ de ancho, se conformó por los muros (MU0213, MU02-08, MU02-12 y MU02-10) (fig. 8) y se asocia con los vanos (VA02-02 y VA02-01). Se observó que los muros (MU02-13 y MU0208) presentan remodelaciones, uno de ellos (MU02-08) inicialmente estuvo enlucido de amarillo. Asimismo, en el vano (VA02-01) se halló una pequeña rampa que se renovó en al menos tres oportunidades, éstas se articularon con la Unidad Arquitectónica 07 en diferentes momentos.

\section{Unidad Arquitectónica 02}

Antesala de $3.40 \mathrm{~m}$ de largo y $0.90 \mathrm{~m}$ de ancho, se conformó por los muros (MU02-13, MU02-08, MU02-12 y MU02-07) (fig. 8) se asoció a los vanos (VA02-03 y VA02-02), en la esquina suroeste sobre la superficie del piso se hallaron restos de quemas rituales, asociados con algunos fragmentos de cerámica, moluscos y peces. Lamentablemente, el piso fue completamente limpiado antes de ser rellenado. También es de notar, que los muros (MU02-07 y MU02-12) fueron remodelados en más de una oportunidad.

\section{Unidad Arquitectónica 03}

Recinto rectangular de $5.04 \mathrm{~m}$ de largo y 3.24 $\mathrm{m}$ de ancho, se conformó por los muros (MU0213, MU02-08, MU02-07 y MU02-06) (fig. 8) se asoció con los vanos (VA02-03 y VA02-04), debido a la buena conservación del piso se registró la presencia de varios hoyos pequeños

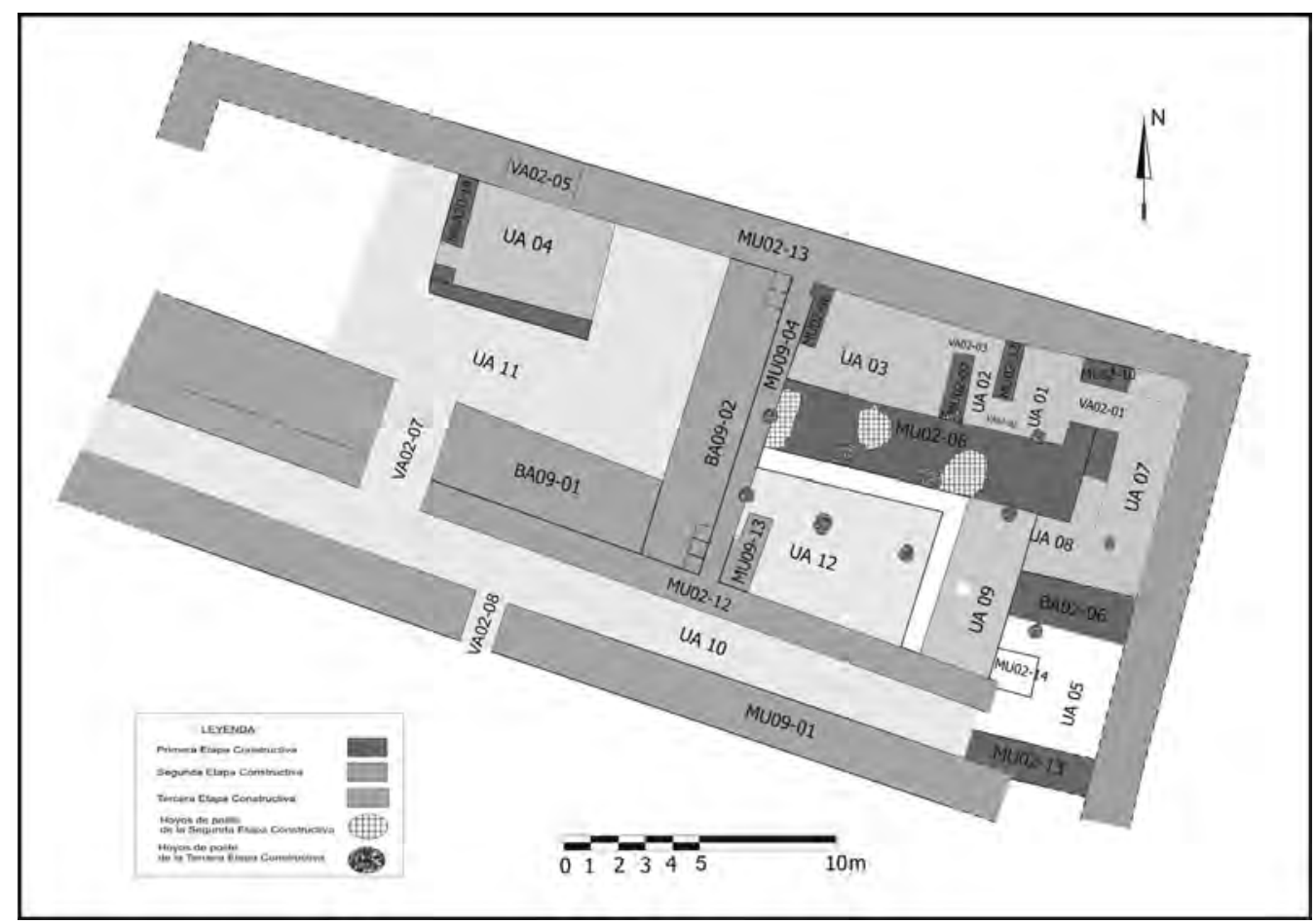

Figura 8. Plano de planta de la Plataforma IV con las principales Unidades Arquitectónicas definidas. 
de ofrendas cuyos diámetros variaron entre 7 a $16 \mathrm{~cm}$, del interior se recuperaron fragmentos de cerámica, moluscos, vegetales, vértebras de pescado, carbones, restos de coleópteros e hilos de textiles. Muchos de estos hoyos pequeños se encontraron sellados por una capa delgada de barro y parecen haber sido elaborados durante la limpieza del recinto momentos previos a la clausura final. Habría que acotar que los hoyos tienen una profundidad de 8 a $21 \mathrm{~cm}$ y no poseen un patrón de distancias.

\section{Unidad Arquitectónica 04}

Recinto rectangular de $6.10 \mathrm{~m}$ de largo (probablemente) y $4.10 \mathrm{~m}$ de ancho. Se conformó por los muros (MU02-08, MU20-14) y muy probablemente a otro muro aún no expuesto que delimitaba el lado este, se asoció a un piso de regular estado de conservación y al acceso principal (VA02-05) de la Plataforma IV (fig. 8). En las esquinas se hallaron abundantes acumulaciones de fragmentos de adobes (RA) y sobre el piso restos de una cesta con barro en su interior, asimismo, se recuperaron varios fragmentos de una vasija con pintura amarilla. Otro detalle interesante es que en ambos lados del vano principal se hallaron hoyos sobre el piso, los que al parecer correspondieron a postes que sirvieron para sostener una probable puerta.

\section{Unidad Arquitectónica 07}

Recinto alargado a modo de pasadizo de 7.30 $\mathrm{m}$ de largo y $2,70 \mathrm{~m}$ de ancho aproximadamente (dado que por el lado este no se logró definir el muro límite). Se conformó por los muros (MU02-08, MU02-13) y la banqueta (BA0206) (fig. 8), se asoció con el vano (VA02-01) y una rampa. Este recinto se encuentra orientado en dirección norte - sur y se halló en mal estado de conservación, sin embargo, se pudo definir al menos tres remodelaciones de la rampa asociado con el engrosamiento del muro (MU02-10).

\section{Unidad Arquitectónica 08}

Pasadizo pequeño definido parcialmente, de 1.58 $\mathrm{m}$ de largo y $1.12 \mathrm{~m}$ de ancho con dirección este - oeste, se encuentra conformada por los muros (MU02-08), la banqueta (BA02-06) y la rampa (RA02-05) (Fig. 8). Se articuló con la Unidad Arquitectónica 07 mediante el uso de un vano de acceso (VA02-04). Este recinto conduce a la parte alta de la banqueta (BA02-06).

\section{Unidad Arquitectónica 05}

Recinto rectangular de $26 \mathrm{~m}$ de largo y $8 \mathrm{~m}$ de ancho aproximadamente (fig. 8), debido a que existe una superposición de otras etapas constructivas no fue posible su definición exacta. Gran parte del piso original y de otras estructuras (BA02-06) fueron destruidas y usadas para rellenar los recintos de la Primera Etapa Constructiva (fig. 4), sin embargo, se ha logrado registrar al menos dos momentos de uso del piso, las evidencias arquitectónicas indican varias remodelaciones que han sido borradas por un último evento destructivo. Este recinto a modo de pequeña plataforma se conformó por los muros (MU02-08 y MU02-14) y la superficie de la banqueta (BA02-06) la cual se articulaba mediante la Unidad Arquitectónica 08.

\section{Unidad Arquitectónica 09}

Se trata de una plaza cuadrangular (fig. 10 y 8) que se encuentra superpuesta por otras etapas constructivas, lo que hace difícil su definición exacta, las dimensiones aproximadas es de $39.45 \mathrm{~m}$ de largo y $39.07 \mathrm{~m}$ de ancho, se encuentra asociada con algunos hoyos de postes muy profundos, estos se hallan equidistantes unos de otros entre $4.07 \mathrm{~m}$ y $3.70 \mathrm{~m}$ en dirección este-oeste (fig. 8), el piso de este recinto tiene dos momentos de uso, en ambos casos los acabados no son muy buenos como en otros recintos. Asimismo, sobre la superficie se hallaron acumulaciones de barro y adobes fragmentados (fig. 4), En la ladera este se recuperó frag- 
mentos de cerámica impregnadas con restos de comida. Actualmente solamente se observa el muro (MU02-13), mientras que los límites de los muros este y oeste en los extremos de las laderas han desaparecido.

\section{Unidad Arquitectónica 10}

Pasadizo largo de aproximadamente $40 \mathrm{~m}$ de largo y $2 \mathrm{~m}$ de ancho, debió de continuar hasta ambos extremos de la ladera (Fig. 8), se conformó por los muros (MU02-12 y MU09-01) en cada uno de ellos se hallaron vanos de accesos (VA02-07 y VA02-08) que articularon el tránsito hacia la Plataforma V.

\section{Unidad Arquitectónica 11}

Plaza pequeña de forma rectangular (figs. 7 y 8), aproximadamente de $30.60 \mathrm{~m}$ de largo y $11.60 \mathrm{~m}$ de ancho, se conformó por lo muros (MU09-04, MU02-13 y MU02.12) y dos banquetas (BA09-01 y BA09-02) elaboradas en diferentes momentos constructivos. El recinto se asoció con un pasadizo (Unidad Arquitectónica 10). La plaza al parecer se conformó en tres momentos de construcción; el primero cuando se construyó la banqueta (BA09-02) con un piso, en un segundo momento se adosó la banqueta (BA09-01) con otro piso, para el último momento elaborarse una pequeña rampa sobe el vano (VA02-07) que se asoció a una superficie levemente alta con la Unidad Arquitectónica 10. Lo más resaltante de esta plaza es que en algún momento casi todas las estructuras estuvieron enlucidas de amarillo y que posteriormente con las remodelaciones se dejo de lado tal costumbre. El ingreso principal se realizó por el vano (VA02-05) mediante un juego de rampas que se iniciaban en la parte baja de la Plataforma III.

\section{Unidad Arquitectónica 12}

Plataforma rectangular de $25 \mathrm{~m}$ de largo y 24.40 $\mathrm{m}$ de ancho, se conformó por los muros (MU02. 13, MU02-12 y MU09-04) también se encontró asociada al muro (MU09-13) la cual probablemente corresponda a una remodelación del recinto (Fig. 8).

En la superficie de la plataforma se hallaron cuatro columnas de postes de cuatro filas cada una, es posible que el número de postes haya sido mayor, dado que parte del lado este de la plataforma ha desaparecido. El piso del recinto fue remodelado en al menos tres oportunidades, registrándose varias refacciones, tiene un fino acabado superficial con varios hoyos pequeños de ofrendas cuyos diámetros variaron entre 5 a $16 \mathrm{~cm}$ y una profundidad de 7 a $21 \mathrm{~cm}$, estos hoyos no tenían un patrón establecido y fueron registrados básicamente en los dos últimos pisos. Los hoyos contenían fragmentos de moluscos, carbón, vértebras de pescado, vegetales no identificados, tusas de maíz, coleópteros, hilos de algodón, pupas de mosca, un fragmento de cerámica y una piedra color blanco. El acceso a la plataforma se realizó por unas escalinatas adosadas a los muros (MU02-13 y MU02-12) el cual sólo quedó una evidencia en el lado sur.

\section{Definición DE LAS ETAPAS Y MOMENTOS CONS- TRUCTIVOS}

Es necesario señalar que antes de conformarse la Primera Etapa Constructiva, el aspecto de la Plataforma IV se caracterizó por el funcionamiento de un pasadizo enlucido de amarillo conformado por los muros (MU02-13 y MU0208), el ingreso a este recinto se realizó por el vano (VA02-05) el cual se asoció con un piso más temprano a las ofrendas de hoyos pequeños. El acceso hacia el área más importante de la plataforma siempre se realizó por el vano (VA02-01) que debió de interconectarse con otros recintos todavía no excavados (fig. 12). Sin embargo, se observa que los muros (MU0214 y MU02-12) se asociaron a este momento dado que, uno de ellos se encuentra con restos de enlucido amarillo, lo que confirmaría que en esta etapa la pintura amarilla en la arquitectura 
fue generalizada. Posteriormente fueron cubiertos con depósitos de R-A² y de R-43.

\section{LA PRIMERA ETAPA CONSTRUCTIVA O RECINTOS DE ACCESOS RESTRINGIDOS}

El primer momento constructivo se encuentra definido por el funcionamiento de las Unidades Arquitectónicas 01, 02, 03, 04 (fig. 8) y otras de similares características todavía no excavadas en dirección oeste, los recintos se articularon mediante vanos o accesos manifestando un aspecto restringido y sinuoso, probablemente con el objetivo de que los transeúntes cumplan con ciertas reverencias conforme se acercaban al sector más importante de la plataforma (figs. 3 y 11). Un vano de acceso (VA02-01) interconectaba estos recintos con una especie de pasadizo (Unidad Arquitectónica 07) que luego en dirección este - oeste (Unidad Arquitectónica 08) ascendía a una pequeña plataforma ${ }^{4}$ (Unidad Arquitectónica 05) adecuada para este momento (figs. 8 y 12). El piso original del recinto fue definido por algunos rezagos de la superficie original, por otro lado, el muro (MU02-08) debió de alcanzar una mayor altura por encima de la Unidad Arquitectónica 05, lo más probable es que todos los recintos pequeños se encontraron techados. Al final de este momento, se decide cambiar el aspecto de la pequeña plataforma (Unidad Arquitectónica 05) para ello fue clausurado la Unidad Arquitectónica 08 mediante un emparrillado de adobes y se desarrolló actividades destructivos, muchos fragmentos de pisos y de la banqueta (BA02-06) fueron encontrados sobre la rampa de acceso (RA02-04), también es muy probable que todas estas destrucciones fueran destinadas al relleno de las Unidades Arquitectónicas 01, 02, 03, 04 y 05.
En el Segundo Momento Constructivo continuó funcionando las Unidades Arquitectónicas 01, 02, 03, 04 y 05 (fig. 3) pero con la superficie de un nuevo piso, fragmentos de una rampa en la Unidad Arquitectónica 07 demostró que el acceso continuó funcionando por este sector para acceder a la Unidad Arquitectónica 05.

En el Tercer Momento Constructivo, los recintos pequeños no sufrieron alteraciones en su conformación, probablemente se remodelaron algunos muros pero los espacios no cambiaron. En la Unidad Arquitectónica 07 se remodeló una de las rampas, la que se originó a mitad del recinto y se dirigió a la parte alta de la pequeña plataforma.

En el Cuarto Momento Constructivo ocurren algunos cambios, en la Unidad Arquitectónica 07, se realizaron adosamientos al interior de los muros (MU02-13 y MU02-08), el recinto es rellenado y gana altura, pues se construye una pequeña rampa en el vano (VA02-01). Lamentablemente, fue imposible correlacionar otros cambios dado que la destrucción en la ladera este borró toda evidencia.

En el Quinto Momento Constructivo los espacios arquitectónicos no variaron en su conformación, se construyó un nuevo piso que sirvió de superficie a todos los recinto pequeños en la parte baja, es en este momento o en el abandono del uso del piso donde se realizó el ritual de ofrenda de hoyos pequeños, también se elaboró otra rampa pequeña (RA02-03) en el vano (VA02-01) lo que indica que la Unidad Arquitectónica 07 se encontró a mayor altura que el momento anterior. También se realizaron actividades de quema ritual en los recintos pequeños acompañados de ingesta de comida, otras actividades parecen corresponder al des-

2 Relleno de adobes conformado básicamente por fragmentos de adobes, tierra color beige, en algunos casos fragmentos de pisos y banquetas, además contiene poco material cultural. Que en adelante denominaremos con la sigla (R-A).

3 Relleno conformado básicamente de cantos rodados y arena color gris, con pocos materiales culturales. Que en adelante lo denominaremos con la sigla (R-4).

4 Al parecer la Banqueta (BA02-06) funcionó inicialmente a un momento anterior, probablemente con una de las superficies que se encuentra por debajo del piso con las ofrendas de hoyos pequeños. 




Figura 9. Reconstrucción hipotética de la Tercera Etapa Constructiva.

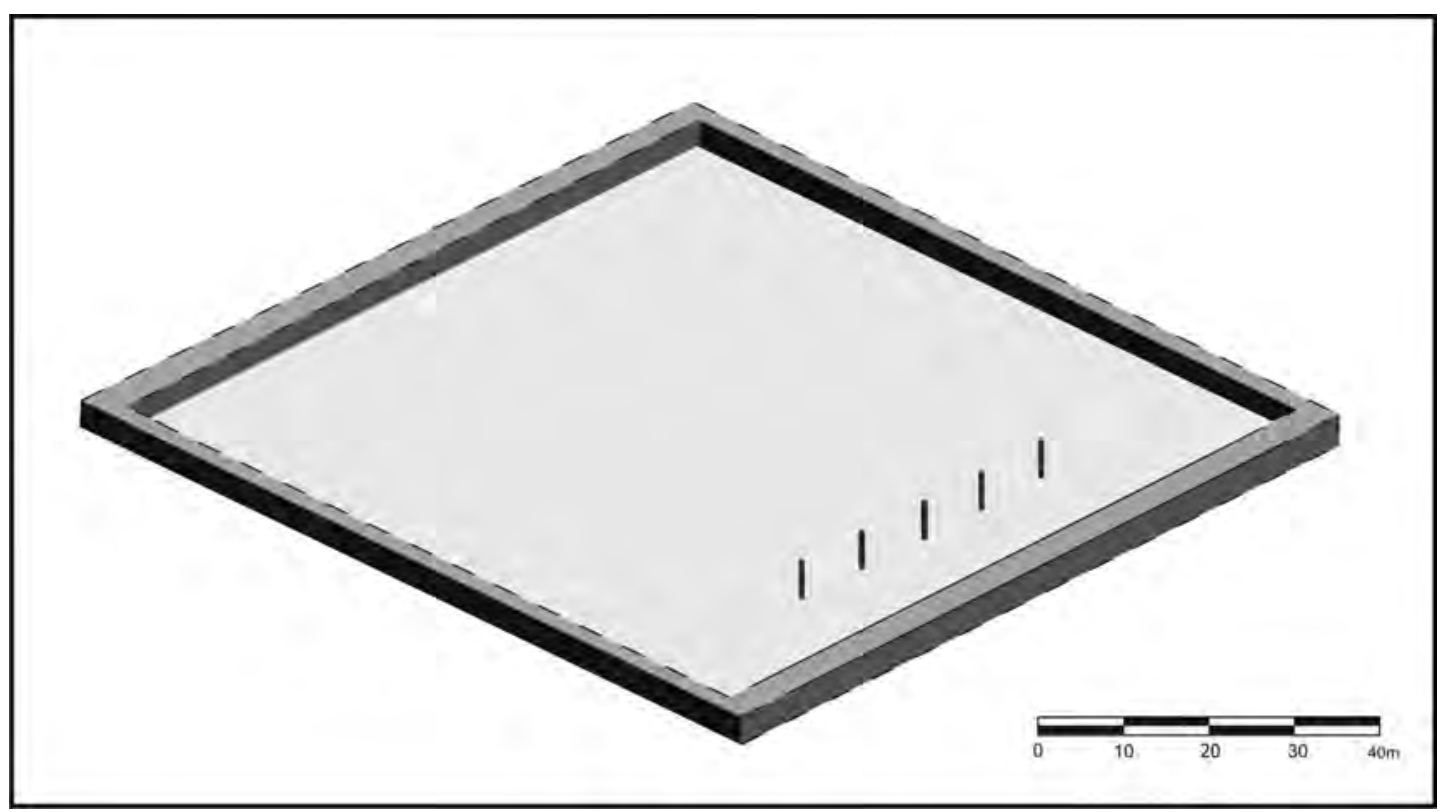

Figura 10. Reconstrucción hipotética de la Segunda Etapa Constructiva. 
montaje de los techos que cubrían los recintos, pues en los paramentos de los muros se registraron varios surcos desordenados en dirección vertical, sumado a ello podemos decir que en los recintos se hallaron fragmentos de vigas de techo. Como colofón se realizaron destrucciones masivas en toda la Plataforma IV, los recintos fueron cubiertos con depósitos de R-A (fig. 4). Asimismo, se ha comprobado que estos rellenos son resultados de las destrucciones de la arquitectura (Ríos 2007: 10), dado que, se recuperaron abundantes fragmentos de pisos, banquetas, y en algunos casos improntas de quincha con enlucidos finos lo que indica que también existieron estructuras perecibles en algún sector de la Plataforma IV.

\section{LA SEGUNDA ETAPA CONSTRUCTIVA O ETAPA DE} LAS REMODELACIONES

Se define por la presencia de la Unidad Arqui- tectónica 09 (fig. 10), es posible que la conformación de este recinto corresponda a un momento de remodelaciones drásticas en la arquitectura de las plataformas adyacentes, pues la superficie inicial de este recinto se prolongó en dirección sur hasta la Plataforma V, ello se infirió correlacionando los elementos arquitectónicos al interior de unas tumbas que se intruían en el muro (MU09-01). Es decir, en estos momentos las Plataformas IV y V no parecen tener una apariencia escalonada.

Otro detalle a resaltar es la asociación de hoyos de postes muy profundos, estos probablemente se ubicaron en toda la superficie de la plaza, los cuales se han logrado definir solamente cinco que se encuentran entre $4.07 \mathrm{a}$ $3.70 \mathrm{~m}$ de distancia, uno de estos hoyos se encontró superpuesto por el muro (MU09-04) lo que indicaría con seguridad que corresponden a la Segunda Etapa Constructiva. Lamentable-

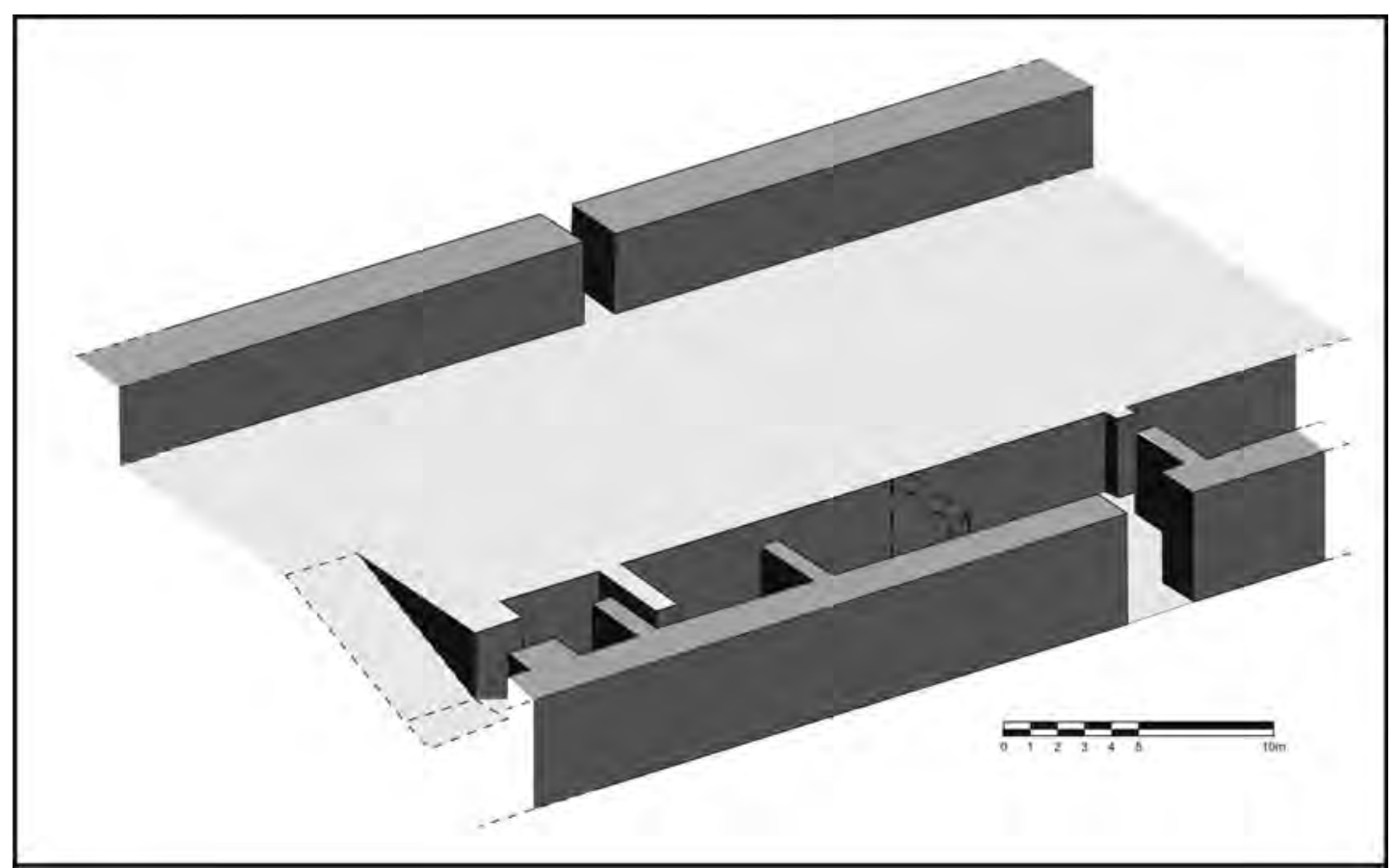

Figura 11. Reconstrucción hipotética de la Primera Etapa Constructiva. 





mente no se pudo asociar exactamente a qué momento constructivo correspondieron, pero es de suponer que fueron concebidos desde su construcción inicial de la plaza.

El Primer Momento Constructivo se definió por la elaboración de un piso, que cubre a un delgado depósito de R-4 (fig. 12), que a su vez nivela algunas depresiones de la anterior etapa constructiva. El piso en mención también selló varias estructuras de la etapa anterior, en esta superficie se han registrado claras evidencias de producción de barro adheridos al piso, también en dirección este se registraron algunos sectores donde existen concentraciones de fragmentos de cerámica asociados con regular cantidad de materiales orgánicos, (vértebras de pescado y moluscos). Es probable que en este momento se hayan realizado más de una actividad distinta a la producción de barro, también es frecuente el hallazgo de acumulaciones de adobes fragmentados probablemente para el reciclado de estos (fig. 5).

En el Segundo Momento Constructivo se mantuvo los límites de la plaza y se elaboró un nuevo piso cubriendo el anterior, al parecer en la ladera este se construyeron algunas estructuras eventuales pues se hallaron solamente la base de un muro en dirección norte sur, es posible que también pueda corresponder al muro que delimitaba la ladera.

En el Tercer Momento Constructivo se construyó un nuevo piso en cuya superficie también se registraron restos orgánicos y cenizas pero en menor cantidad que el Primer Momento Constructivo. El nuevo piso no tiene buena consistencia, parece corresponder a una elaboración sin mucho cuidado o de manera apresurada. Es probable que exista la elaboración de un nuevo piso, pues solamente pudo evidenciarse en un área pequeña en el sector este, cabe la posibilidad también que corresponda simplemente a una refacción del piso anterior.
LA TERCERA ETAPA CONSTRUCTIVA O PLAZA PINTADA DE AMARILLO CON PLATAFORMA

En el Primer Momento Constructivo se edificaron las Unidades Arquitectónicas 10 y 12 configurándose una Plataforma Rectangular, es posible también que antes de este momento exista una remodelación con enlucido amarillo. En tal sentido, se conformó desde sus inicios como una plataforma pequeña asociada con una plaza con una sola banqueta (BA09-02) en el lado este. Al parecer, a partir de este momento en adelante el acceso a la Plataforma Rectangular (Unidad Arquitectónica 12) se realizó mediante escalinatas ubicadas al Sureste y Noreste.

En el Segundo Momento Constructivo se remodeló el muro (MU09-04), la Plataforma Rectangular gana en altura mediante un depósito de R-4 (fig. 12) y se elaboró un piso de acabado fino asociado a postes equidistantes, siendo la distancia promedio en las columnas de $2.70 \mathrm{~m}$ y en las filas de 3.20 a $3.30 \mathrm{~m}$, este patrón se repite hasta la clausura definitiva del recinto, el cual es muy diferente al patrón de la anterior Etapa Constructiva; es posible que haya existido una o dos filas más debido a que en este sector de la ladera ha desaparecido toda evidencia. Un detalle interesante fue el hallazgo de un poste en posición invertida, aunque no ha sido posible asociarlo a un momento constructivo específico, suponemos fue colocado probablemente como ofrenda asociada a uno de los últimos momentos de construcción, pues se encuentra casi en la parte media de este recinto, atribuyéndoseles connotaciones especiales. Asimismo, sobre la superficie se lograron identificar varios hoyos pequeños de ofrendas.

En el Tercer Momento Constructivo se elaboró otro piso de fino acabado en la plataforma, en este también se hallaron hoyos de postes y fue reutilizado en al menos una oportunidad.

En el Cuarto Momento Constructivo se elaboró un nuevo piso sobre la superficie de la plataforma. Asimismo, se remodeló el muro (MU09-04). 
En el Quinto Momento Constructivo se elaboró un nuevo piso (PI09-09) (fig. 12), el aspecto no cambió, se mantuvo el uso de los postes, se registraron varias ofrendas de hoyos pequeños, en algunos sectores se realizaron refacciones del piso.

En el último momento constructivo no cambió en nada el aspecto de la plataforma, la presencia de los postes y de hoyos pequeños de ofrendas continuó. También es posible observar refacciones del piso en ciertas áreas que se desgastaron. La presencia de hoyos pequeños de ofrendas parecen fueron actividades que auguraban la clausura final de este recinto.

\section{LA CUARTA ETAPA CONSTRUCTIVA}

Se define por la evidencia de un fragmento de piso que selló al muro (MU02-12) previo a un depósito de R-4 que cubrió completamente a las Unidades Arquitectónicas 09, 11 y 12. Habría que señalar que de este relleno se recuperaron algunos fragmentos con las clásicas decoraciones Nievería, lo cual fecharían a esta etapa dentro de la época IB del Horizonte Medio. Al parecer, el nuevo recinto que se conformó correspondería a un plaza que tuvo sus límites con los muros (MU02-13 y MU09-01), también durante esta etapa la Plataforma IV gana en altura al mismo nivel que la Plataforma V, debe destacarse también, que el muro (MUO2. 13) después de esta etapa sufrió una destrucción notable, que bien podría asociarse a gran parte de la plataforma IV; y luego en su remplazo se construyó un muro atípico, en los restos de esta destrucción también se hallaron fragmentos de estilo Nievería.

TéCnica CONSTRUCTIVA DE LA ARQUiteCtura en la Plataforma IV y las características ESPACIALES DE LAS ETAPAS CONSTRUCTIVAS

En el centro ceremonial se ha logrado diferenciar tres grandes fases constructivas que se caracterizan por la superposición de estructuras y la diferencia en el uso de elementos construc- tivos. La Tercera Fase (la que nos interesa) se caracterizó por la máxima expansión arquitectónica alcanzada por el centro urbano (fig. 1b), y también por que se encuentra asociada a cerámica de las fases 7, 8, 9 del estilo Lima así como de Nievería (Flores 2005: 54-57). Esta fase se encuentra conformada por una serie de etapas constructivas y remodelaciones constantes en la arquitectura, que en algunos casos es posible definir por: la variación en la forma de los espacios arquitectónicos; el uso de adobitos paralelepípedos rectangulares y los recintos rellenados con una variedad de depósitos (ver Flores 2006: 51-53).

Aunque, sabíamos que la Plataforma IV correspondió a esta gran fase constructiva también intuíamos que existía una secuencia constructiva que deberían tener diferencias temporales y probablemente funcionales. Además, teniendo en cuenta que las fases 7, 8 y 9 del estilo Lima no ha sido posible segregarlo en segmentos de tiempo con validez cronológica (Lavalleè 1966; Montoya 1995; Guerrero y Palacios 1994; Narváez 2006; Segura 2001; Ríos 2008) tal como Patterson (1966) las planteó, fue necesario orientar nuestras investigaciones hacia la caracterización de la arquitectura y el manejo de los espacios, para la contrastación respectiva con otros centros ceremoniales contemporáneos con Pucllana. En tal sentido, uno de los pocos trabajos cuya propuesta se mantiene todavía vigente es la Tesis de Bachiller sustentada por Alarcón (1971), en dicha investigación se propuso Tres Fases Constructivas de la Huaca San Marcos, donde la Primera Fase Constructiva fue elaborado con la técnica "c" y es descrita como:

La técnica usada para unir los adobes, es de lo más cuidadoso, elegante y uniforme comparando con las técnicas usadas en las construcciones posteriores; se caracteriza por la poca cantidad de mortero usada para unir los adobes, limpie$z a$ en los paramentos, y selección en los adobes puesto que manifiestan una marcada uniformidad y colocados a modo de libros en un estante. 
[...] De este modo se han construido lienzos regulares, que adosados unos a otros, conforman los grandes muros trapezoidales (Alarcón 1971: 100).

Dicha técnica adjudicada inicialmente entre los 400 y 500 d.C., en una publicación (ver Narváez 2000) realmente correspondería a la época 1A del Horizonte Medio, dado las asociaciones de la arquitectura con materiales de la fases Lima 9 y Nievería, mientras que la técnica "b" de Alarcón correspondería a la época 2 del Horizonte Medio según la cerámica asociada (Narváez com. pers. 2009).

Posteriormente, Alarcón hace una aclaración muy importante señalando que los muros de la técnica "a y b" tienen elementos en común como su forma trapezoidal y el modo de colocar los adobes, diferenciándose por el tamaño y volumen de los muros, siendo los de técnica " $b$ " de menores dimensiones que los del "a", así también por la perdida del criterio de selección de los adobes; pero la diferencia fundamental es la concepción de un nuevo patrón constructivo cuya característica es la ausencia de una simetría bilateral (Alarcón 1971: 101). Esta definición técnica de Alarcón se ajusta en gran parte a las características de la arquitectura de la Plataforma IV.

Por otro lado, un inventario de medidas en los adobes fue realizado de los muros que conformaron las Tres Etapas Constructivas, el promedio dio el siguiente resultado: en la Primera Etapa Constructiva (la más temprana) el largo de los adobes resultó $20.1 \mathrm{~cm}$, el ancho $13.9 \mathrm{~cm}$ y el grosor $6.3 \mathrm{~cm}$; en la Segunda Etapa Constructiva no fue posible obtener tales medidas debido a las remodelaciones y ausencia de muros, mientras que en la Tercera Etapa Constructiva (la más tardía) las dimensiones fueron
$19.2 \mathrm{~cm}$ de largo, $13.8 \mathrm{~cm}$ de ancho y $6.5 \mathrm{~cm}$ de grosor, existiendo muy leves diferencias en las dimensiones de los adobes. Estas medidas coinciden en gran parte con los reportes realizados por Kroeber (1954) en el montículo 15 y 16 de Maranga, Fernández (1960) y Rodríguez (1999) en Huaca Tupac Amaru "B". Según las excavaciones en el templo Viejo de Pachacamac los adobes característicos de la época 1 del Horizonte Medio corresponden a formas rectangulares $^{5}$ mientras que en las fases tardías del Período Intermedio Temprano existiría una tendencia a un mayor engrosamiento de los adobes (Franco 2003: 154-161) situación similar parece reportarse en la pirámide de Nievería (Silva 1992: 62) esta evidencia se asemeja mucho a la Segunda Fase Constructiva de Pucllana, donde es común el uso de adobes cúbicos correspondientes a la etapa Lima Medio ${ }^{6}$. En algunos casos se han registrado adobes reutilizados de las fases anteriores dentro de algunos rellenos, ello ocurrió en la ladera este de la plataforma cuando se decidió clausurar varias estructuras momentos antes de conformarse la Primera Etapa Constructiva, es decir cuando probablemente ya se había planificado la construcción de la Unidad Arquitectónica 05, se procedió a la destrucción parcial de la banqueta (BA02-06) y sobre ésta se selló con un panel de emparrillados de adobes, este tuvo como principal objetivo consolidar algunos espacios donde se tenía proyectado construir nuevas edificaciones de cierta importancia. Entre el emparrillado de adobes, se logró recuperar los denominados adobes "pastilla" y de formas cúbicas correspondientes a la fase constructiva II de Pucllana. Lo cierto es que en las tres últimas fases constructivas de la Plataforma IV el uso de adobes rectangulares es absoluta y no demues-

5 Franco y Paredes dan a conocer las dimensiones de los adobes en las fases Temprana, Media y Tardía del Período Intermedio Temprano, pero no mencionan las dimensiones de los adobes de la época 1 del Horizonte Medio.

6 Y si se tiene en cuenta las evidencias de Paredes (2000) en cuanto a la superposición de estructuras de tapia sobre las adobitos cúbicos en el valle del Chillón, tendríamos un panorama donde el uso de diversos materiales y cierta variedad en las formas cúbicas se hacen presente durante el desarrollo Lima Medio y Temprano, es posible que ello corresponda a la naturaleza de los Centros Urbanos durante esta etapa, es decir probablemente funcionaban todavía con cierta autonomía y estaban en un proceso de amalgamiento político entre los valles. 
tran diferencias sustanciales. Por el contrario, los cambios más notables se registraron en la conformación de los espacios arquitectónicos la cual pasamos a exponer en síntesis.

La Primera Etapa Constructiva se conformó básicamente por dos espacios: la primera mediante una especie de pasadizo asociados a varios recintos pequeños (fig. 3 y 11), los espacios son restringidos y sinuosos, aparentemente la única vía de acceso hacia la parte más importante se realizó por el lado este, al parecer todos estos recintos se encontraron techados y por las dimensiones de los recintos se presume debieron albergar a muy pocas personas, casi todos los muros tienen evidencias de remodelaciones, presentan un enlucido fino de color beige y en una primera etapa las evidencias demuestran que estuvieron completamente enlucidos de amarillo. El segundo espacio y al parecer el sector más importante se definió mediante la Unidad Arquitectónica 05 (plataforma pequeña), lamentablemente por la superposición de rellenos y estructuras no fue posible definirlo adecuadamente. Sin embargo, indirectamente se infiere la existencia de estructuras perecibles con enlucidos finos. El acceso principal a la Plataforma IV se realizó por el lado norte mediante un vano (VA02-05). En líneas generales, los ambientes de esta etapa denotan características ceremoniales, a pesar de que en la etapa anterior se habría manifestado con mayor énfasis (debido al fino enlucido amarillo de los ambientes). Las evidencias de quemas rituales desarrolladas en las esquinas de algunos recintos y la presencia de restos de comida antes de la clausura, parecen corresponder a ciertos patrones de conducta denominados "banquetes ceremoniales" (Flores 2005; Ríos 2008). Además, al parecer durante o después de realizado estas actividades fueron complementados con las ofrendas de hoyos pequeños, lo que indica claramente el aspecto ceremonial en este momento.

La Segunda Etapa Constructiva correspondió a una gran plaza ausente de banquetas y de enlucidos pintados (fig. 10), al interior estuvieron asociados a varios postes equidistantes los que debieron de proporcionar sombra en las estaciones de verano y protección de las lloviznas en el invierno. Aunque, no hemos logrado definir exactamente el acceso principal en estos momentos, suponemos debió de realizarse por el mismo vano de acceso de la etapa anterior pero a un nivel más elevado. Las evidencias halladas nos demuestran que las actividades cambiaron drásticamente con respecto a la etapa anterior, acumulaciones de barro impregnados en la superficie de los pisos y montículos de adobes fragmentados (fig. 5) probablemente para ser reelaborados fueron elementos para inferir actividades de producción de barro. Es posible que estructuras temporales se hallan erigidos en estos momentos destinados a actividades complementarias de la producción de barro, por otro lado, los pisos definidos no presentan buenos acabados ni son de buena manufactura, pareciera que tales estructuras fueron elaborados eventualmente por un tiempo no muy prolongado o fueron realizados bajo cierto apremio.

Un detalle que pensamos vale la pena resaltar es la dimensión de la plaza, pues no solamente se restringe a la Plataforma IV si no que también abarca gran parte de la Plataforma V, lo que nos lleva a comprender relativamente cómo se realizó el proceso constructivo del centro ceremonial, pues al parecer las remodelaciones o la construcción de nuevos recintos debieron realizarse en los alrededores de esta plaza, muchas personas debieron de participar en múltiples actividades como el preparado de barro y elaboración de adobes, el traslado de materia prima como el agua, tierra y adobes fragmentados, los arquitectos habrían planificado áreas para la construcción de nuevos ambientes de acuerdo a las necesidades de la clase sacerdotal. En tal sentido, aunque todavía no estamos seguros si estos comportamientos corresponden a actividades calendarizadas, lo cierto es que la parti- 
cipación de los feligreses al servicio del centro ceremonial fue de características corporativas y que cíclicamente ambientes de características ceremoniales dieron paso a espacios de otras características. Sin embargo, las actividades productivas no necesariamente se mantuvieron asépticas durante todo este proceso, al parecer actividades de ingesta de comida de características rituales también fueron realizados antes del abandono de la plaza, pues vasijas completas o restos de estas conteniendo alimentos fueron arrojados en la superficie ${ }^{7}$, ello debe de entenderse que si bien el espacio en estos momentos no es sagrado, las actividades realizadas son de suma importancia y conllevan a la realización de ciertos actividades que pueden catalogarse como manifestaciones rituales.

La Tercera Etapa Constructiva se conformó por dos espacios bien diferenciados (fig. 9): una de ellas fue la Plaza Pintada de Amarillo adosados con banquetas en el lado sur y este, donde el acceso principal se realizó por un vano en el muro norte, hacia el sureste se ubicó unas escalinatas y otra debió de existir al noreste las que accedían a la parte principal de la Unidad Arquitectónica 12. Esta plataforma al parecer en sus inicios también estuvo enlucida de amarillo, la presencia de postes apoyaría la idea de que se encontraba techada, el buen acabado de los pisos y las ofrendas de hoyos pequeños manifiestan su carácter sagrado, así como la ofrenda de un poste invertido, sin duda alguna los grupos de élite de mayor jerarquía debieron de ubicarse en este lugar; mientras que otros grupos de menor rango se habrían reunido en la Plaza Pintada de Amarillo para participar de las actividades rituales o probablemente para la coordinación en la toma de decisiones importantes. La Plaza Pintada de Amarillo (Unidad Arquitectónica 11) por sus dimensiones establecidas no albergó a demasiadas personas, probablemente no más de un centenar, hasta cierto punto el acceso debió de ser restringido, aunque la presencia del enlucido denota una cierta sacralidad al inicio de su conformación, no existen mayores evidencias sacras como en la Plataforma Rectangular (Unidad Arquitectónica 12). Un detalle muy interesante a resaltar es el cambio de orientación de los componentes arquitectónicos, pues hasta el momento en las excavaciones del Centro Urbano de Pucllana siempre los componentes arquitectónicos (banquetas o plataforma) más importantes se ubicaron en los lados sur u oeste (Ríos 2008), mas no así, en el lado este como se encuentran en la Tercera Etapa Constructiva, otra estructura de similares características al parecer contemporáneas con esta etapa fueron definidas en la Plataforma V (Flores com. pers. 2008) lo que hace suponer, existe una variación drástica en la orientación de los espacios importantes en estos momentos.

\section{CAMBIOS REFLEJADOS EN LA ARQUITECTURA Y AL-} GUNOS ASPECTOS DE LA SOCIEDAD LIMA

La arquitectura definida en la Plataforma IV nos ha demostrado que existen innovaciones en las fases tardías del desarrollo arquitectónico del centro ceremonial, estas no solamente corresponden a la concepción diferenciada de los espacios, si no también a manifestaciones que se evidencian en la sociedad Lima. El caso de la Huaca San Marcos sugiere que la fase "III" mantuvo características básicamente ceremoniales, mientras que en la fase "II" cambiaron a centro ceremonial y civil (Alarcón 1971: 104-105). Las evidencias de la Plataforma IV en cierto modo mantiene ciertas características con los postulados de Alarcón, como hemos manifestado líneas arriba la Primera Etapa Constructiva mantiene características ceremoniales, y es casi seguro que tales manifestaciones habrían sido más acentuadas en etapas anterio-

7 Durante las excavaciones realizadas fue posible recuperar algunos fragmentos que empezaron a unirse reconstruyéndose en un 25 ó 30\% de su integridad, lamentablemente por el espacio restringido de la ladera no fue posible recuperar más fragmentos que se intruían en el perfil de las estructuras. 
res, es necesario recordar que durante las fases II y III de la Huaca San Marcos se reportaron recintos enlucidos de amarillo (ibid.: 102) aspecto recurrente también en el Templo Viejo de Pachacamac con una variación ocre-amarillo sobre todo en los sectores de mayor importancia (Franco y Paredes 2003: 185). Ello implicaría que las estructuras tardías de la Plataforma IV revistieron gran importancia en las decisiones políticas más que religiosas del centro urbano. Si bien es cierto, la pérdida de las atribuciones ceremoniales es posible percibirlo en la fase II de San Marcos 8 y fase III de Pucllana, se podría plantear que durante la época $1 \mathrm{~A}$ del Horizonte Medio empiezan a acentuarse estas innovaciones en la arquitectura y la cerámica. Ello se fundamenta básicamente en la contrastación de los datos obtenidos entre la Tercera Etapa Constructiva de la Plataforma IV y la Gran Plaza con Banquetas (ubicado en el Complejo Noreste del Centro Urbano). La Gran Plaza con Banquetas se conformó para albergar grandes cantidades de personas, es decir, mantiene características eminentemente públicas, en el desarrollo arquitectónico el sector más importante siempre se ubicó en el lado oeste de dicha plaza, el análisis de vestigios culturales depositados a modo de ofrendas sobre una rampa la ubicaron en la época 1A del Horizonte Medio (Ríos 2008). La presencia de fragmentos Nievería Temprano con ausencia de motivos foráneos (Ccencho 2006; Ríos 2008) ratificarían la ubicación temporal en esta época.

Por otro lado, la presencia de fragmentos Nievería con claras evidencias de motivos foráneos fueron recuperados del siguiente piso que selló la Tercera Etapa Constructiva de la Plataforma IV; en tal sentido, se puede plantear la conformación relativamente tardía de las Unidades Arquitectónicas 11 y 12 (Tercera Etapa Constructiva de la Plataforma IV) con respecto a la Plaza con Banquetas. La importancia de estas correlaciones implica que es posible distinguir y ubicar sectores definidos en el Centro Urbano de Pucllana donde pueden registrarse los precisos instantes en que se manifiestan por primera vez los contactos con grupos humanos de los andes ayacuchanos. Un evento similar de esta naturaleza fue reportado en las excavaciones de Cajamarquilla cuando se evidenció un declive y abandono del lugar (Mogrovejo 1999: 236).

En consecuencia, las innovaciones manifestadas en la arquitectura como el cambio de la orientación de los recintos de gran importancia y la pérdida de las connotaciones sagradas, se encuentran relacionados a momentos de transformaciones en el orden ideológico - político que se estaban desarrollando durante esta época.

Las características espaciales de la Plataforma IV, nos hace inferir probablemente concentraciones de grupos reducidos de personas, en donde el acceso habría estado restringido a personajes representativos de los componentes sociales, probablemente para tratar asuntos concernientes a las decisiones compartidas con la élite sacerdotal, la que presumiblemente se hallaban en la parte más alta de la plataforma (Unidad Arquitectónica 12).

Es necesario recordar que la sociedad Lima y casi toda el área andina a finales de la época 8 del Período Intermedio Temprano experimentaron una época de alteraciones climáticas mediante eventos de sequía y períodos húmedos (Shimada et al. 1991), la sequía más intensa se habría desarrollado en casi toda la época $1 \mathrm{~A}$ del Horizonte Medio, los efectos de estos fenómenos climatológicos habrían afectado la economía básicamente agraria de la sociedad Lima. Sin embargo, algunas evidencias analizadas en Pucllana han demostrado que el centro urbano no fue abandonado durante estas anomalías, por el contrario el desarrollo arquitectónico y ocupaciones posteriores continuaron momentos

8 A pesar que corresponde a la época 2 del Horizonte Medio (Narváez com. pers. 2009), es de suponer que los cambios más drásticos en la sociedad resultado de las influencias Huari ya habían pasado. 
después de la mayor sequía, lo que podríamos sostener que tales fenómenos solamente fueron condicionantes en las profundas transformaciones sociales que se realizaron en la época $1 \mathrm{~B}$ del Horizonte Medio.

Por otro lado, la mayor extensión arquitectónica del Centro Urbano de Pucllana se desarrolló durante la etapa Lima Tardío, esta se habría iniciado durante la época 7 del Período Intermedio Temprano, en precisos momentos cuando se manifestaban diversos cambios en los patrones de asentamientos en la costa central, muchos centros ceremoniales son abandonados como Cerro Culebras (Patterson 1966), Playa Grande (Tabío 1965), Cerro Media Luna (Quilter 1982) y empezaron a conformarse grandes montículos en los llanos costeros como Copacabana, La Uva, y un poco tardíamente Vista Alegre y Huaca Trujillo (Paterson 1966), es decir, se desarrollaron grandes centros urbanos que habrían sido resultado de transformaciones en los niveles político y económico (Silva 1996: 170), es posible que estas innovaciones fueran el resultado de las interacciones a niveles regionales que ingresaron las sociedades durante esta época (Shady 1982). La ubicación estratégica de la costa central habría favorecido en dinamizar las transacciones de productos de norte a sur y con ellos también las innovaciones ideológicas, pues como se nota claramente, aspectos como la arquitectura monumental del norte fueron plasmados en los centros urbanos, el colorido de las tradiciones alfareras del sur fueron adheridos, influencias del Callejón de Huaylas también se hicieron notar. En síntesis, las transformaciones en las sociedades de la costa central se habrían iniciado a comienzos de la época 7 del Período Intermedio Temprano, la fuerte interacción producida en estos momentos habrían favorecido notablemente a la recepción y transmisión de nuevas tecnologías e ideologías.

La pérdida del aspecto ceremonial en los Centros Urbanos Lima durante esta época no solamente se puede hacer evidente en la arqui- tectura monumental, también es posible notarlo en la cerámica, pues se observa un mayor énfasis en la producción de cántaros y ollas en las fases tardías desplazando a los platos y vasos típicos de las fases tempranas, las cuales han sido interpretadas como cambios en el nivel ideológico de la sociedad (Ccencho 1999: 150). Se puede deducir que durante la crisis climática el descontento de la población debió de acentuarse: la clase dirigente (sacerdotes) debió de ser cuestionada ante la ineficacia de las plegarias hacia las deidades tutelares; sin embargo, se observa una mayor adhesión de la fuerza de trabajo orientadas a las actividades de la arquitectura monumental, el centro ceremonial crece en volumetría y alcanza su máxima extensión espacial, se evidencian además, un exacerbado énfasis en las remodelaciones de los recintos construidos, manifestado en la destrucción de la arquitectura, adosamientos de nuevos muros, refacciones de pisos, desmontaje de algunos estructuras etc,. Asimismo, puede plantearse una mayor presencia de nuevos grupos de artesanos adhiriéndose al sistema productivo de la cerámica Nievería, no solamente en el caso de Pucllana (Ríos 2008: 250) si no también, en el valle medio del Rímac, ello puede entenderse como respuesta a la demanda en el incremento de las actividades rituales (banquetes ceremoniales y ofrendas de cerámica); además de una mayor producción de los otros alfares de tradición Lima. Ante este panorama; en la primera época del Horizonte Medio 1A, parece evidenciarse los primeros cambios resaltantes a nivel ideológico - político, nuevos grupos de poder parecen estar conformándose dentro de la clase dirigencial en los centros urbanos de la costa central.

Según las excavaciones de la expedición italiana en Cajamarquilla "[...] una primera fase de expansión cultural nazca (Época 1A) sigue un segundo período en el que es la sierra quien exporta sus símbolos y su visión del mundo (Época 1B)." (Cavatrunci 1999: 361). Esta aseveración de Cavatrunci nos parece muy per- 
tinente para abordar el siguiente tema referente a la cronología y su relación con la tradición alfarera Nievería.

Menzel (1968) ubicó al estilo Nievería en la época $1 \mathrm{~B}$ del Horizonte Medio realizando la siguiente acotación, "[...] la alfarería decorativa de la costa central durante la época $1 \mathrm{~B}$ del Horizonte Medio, es llamado aquí estilo Nievería. Es conocido también como «Protolima», «Maranga»y «Cajamarquilla». Sin embargo, no toda la alfarería agrupada bajo estos nombres, corresponden a la Época 1B del Horizonte Me$\underline{\text { dio }}^{9}$ (Menzel 1968: 94). En tal sentido, sobre la base de nuevas evidencias se plantea dos etapas de desarrollo del estilo Nievería una Temprana y otra Tardía (Ccencho 2006: 31), este planteamiento de segregación del estilo Nievería se ha confirmado en las excavaciones de la Gran Plaza con Banquetas al ausentarse los motivos foráneos (Cf. Ríos 2008: Fotos 105-109). Es necesario reiterar que los fragmentos Nievería Temprano fueron recuperados de la Segunda y Tercera Etapa Constructiva mientras que el típico estilo Nievería denominado por Menzel se recuperó solamente $^{10}$ de la Cuarta Etapa Constructiva de la Plataforma ${ }^{11}$ (Fig. 6). Las características estilísticas del Nievería Temprano indican una mayor relación con la región sureña, mientras que en la segunda etapa se hace presente rasgos foráneos de la zona altoandina de Ayacucho (Ccencho 2006: 33). Estos nuevos aportes en la caracterización de la cerámica Nievería nos ofrecen nuevos lineamientos de investigación no solamente en relación a la producción de alfares, sino también a la diferenciación estilística con validez cronológica, dado que en más de una oportunidad se ha cuestionado la secuencia de Patterson sobre todo en las fases tardías
(Lavallè 1966; Montoya 1995; Guerrero y Palacios 1992; Segura 2001; Narváez 2006; Ríos 2008). En tal sentido, se plantea que es posible una segregación con validez cronológica en el desarrollo del estilo Nievería mas no así (por el momento) en el estilo Maranga.

Esta singularidad en la preferencia de representar las innovaciones de la cerámica en ciertos alfares, deben de estar relacionados también a usos específicos de estas vajillas, recordemos que varias vasijas del estilo Nievería fueron encontradas rotas intencionalmente en contextos de ofrendas (Flores 2005: 67). Asimismo, se ha planteado que vasijas de este alfar fueron producidas para eventos rituales de gran trascendencia (Ríos 2008: 281-282), por lo tanto, al parecer la producción y consumo de este alfar parecen estar reservados básicamente para actividades rituales. Lo que nos lleva a pensar que el conocimiento de la tecnología de producción alfarera parece estar siendo manipulada exclusivamente por la clase sacerdotal, es posible que solamente los grupos de élite fueran los principales consumidores de la fina cerámica Nievería. No está por demás decir, que esta cerámica alcanzó un alto grado de demanda a largas distancias y han sido halladas en los valles de Chancay, Huaura, Supe - Pativilca (Shady 1982) y el sitio de San José de Moro (Castillo y Donan 1994) por lo que se infiere empezó a cobrar prestigio en la época $1 \mathrm{~A}$ del Horizonte Medio.

TransformaCIONES SOCIALES EN LA ÉPOCA $1 \mathrm{~A}$ del Horizonte Medio: Una propuesta en base a las eVidencias de Pucllana

Aproximadamente hacia los 550 - 650 d.C., la sociedad Lima había ingresado a una dinámica de desarrollo muy acelerada, sobre la base de

\footnotetext{
9 El subrayado es nuestro.

10 El subrayado es nuestro.

11 Tecnológicamente, varios fragmentos tienen las pastas muy poco tratadas; en algunos casos los diseños Nievería Temprano se encuentran representados sobre pastas delgadas pero de manufactura típica Lima, estas manifestaciones en la cerámica son casi idénticas a los hallados en la Gran Plaza con Banquetas, donde fueron discutidas parcialmente en un trabajo anterior (ver Ríos 2008).
} 
una economía agraria y con la aplicación de un sistema de riego mediante una red de canales había logrado una ampliación máxima de las áreas de cultivo (Mac Neish et al. 1975: 53-54). Muchos de los centros urbanos Lima habían soportado los primeros desequilibrios climatológicos y se encontraban en la más prolongada e intensa sequía. Resultado de estos eventos, se habría producido una desestabilización económica y en tal sentido se habría acentuado la interacción a nivel multi-regional, esta se habría iniciado a comienzos de la época 7 del Período Intermedio Temprano (Shady 1982) intensificándose probablemente a comienzos de la época 1A del Horizonte Medio, como respuesta a tales eventos y a la escases de productos agrarios, el intercambio de productos debió de realizarse a largas distancias, esto se hace evidente en las excavaciones arqueológicas; productos exóticos muy preciados por los Lima fueron utilizados en actividades rituales de gran trascendencia (Ríos 2008) y también en la parafernalia mortuoria (Flores 2005). Es así que los centros urbanos de la costa central se habían conformado bajo una tradición fuertemente religiosa dirigida por una clase sacerdotal durante la etapa Lima Temprano y Medio. Pero qué sucedió con la élite sacerdotal cuando ocurrieron los complejos cambios en el patrón de asentamiento durante los 500 d.C. (Mac Neish et al. 1975: 54)

Líneas arriba se ha manifestado que, sobre la base de las evidencias de los centros ceremoniales de la Huaca San Marcos y Pucllana se postula un cambio en el patrón arquitectónico; cuyas características inicialmente ceremoniales, dieron paso en su fase tardía ha atributos cívico-ceremoniales (Alarcón 1971) enfatizándose notoriamente una mayor adhesión de la fuerza de trabajo en actividades de producción de la cerámica y la arquitectura monumental.

Las evidencias de la Plataforma IV indican que la Primera Etapa Constructiva todavía mantenía características ceremoniales, pero que la declinación ya estaba en proceso y esta se hace más notorio en la Tercera Etapa Constructiva asociados a drásticas remodelaciones arquitectónicas y a la ausencia del enlucido amarillo, en donde no sólo cambió de funcionalidad sino también la ubicación de los sectores más importantes de la arquitectura. Es decir, se puede postular que durante esta época la pérdida del carácter ceremonial y con ellos la merma del poder político de las élites sacerdotales se expresó en los componentes arquitectónicos. En la Tercera Etapa Constructiva los espacios definidos manifiestan dos recintos asociados; pero a la vez diferenciados, que pueden catalogarse como estructuras cívico - ceremoniales. Aunque todavía no se ha correlacionado exhaustivamente estas etapas constructivas con las otras plataformas del centro ceremonial, todo parece indicar que -por las características líneas arriba mencionadas- se diferenciaron notablemente de las otras plataformas: el acceso a los recintos de la Plataforma IV fueron más restringidas a comparación de la Plataforma II y III, los que al parecer siempre funcionaron como plazas abiertas. Los dos componentes arquitectónicos definidos manifiestan funciones diferenciadas en donde la congregación de personas debió de remitirse a solamente grupos pequeños de las élites dirigenciales. Es decir, las audiencias a pequeñas escalas parecen corresponder a las actividades principales en este recinto, mientras que la Plataforma Rectangular pareciera estar diseñada para la ubicación de los sacerdotes participando indirectamente de los acuerdos que se desarrollaron, hipotéticamente se plantea una mayor presencia de grupos seculares que deben de estar vinculándose con las decisiones políticas del centro urbano. Este supuesto, puede ser entendido desde el punto de vista que la sociedad Lima pasaba por la más seria crisis debido a las alteraciones climáticas que desestabilizaron las bases económicas, las soluciones a tal problema, la búsqueda de nuevas fuentes de recursos, e incrementar las transacciones a largas distancias, debieron concitar el interés 
mancomunado de las élites. El desprestigio de la clase sacerdotal gobernante parece manifestarse en la arquitectura, sin embargo, las actividades rituales en los recintos es todavía evidente, actividades como remodelaciones, construcción de nuevos componentes arquitectónicos de mayor magnitud, y en líneas generales, las actividades rituales parecen incrementarse y son notorias en la arquitectura no solamente del centro ceremonial sino también en otros componentes del centro urbano. Es decir, la clase sacerdotal gobernante debió de realizar su máximo esfuerzo para no perder el control de la población al servicio del centro ceremonial. Según Choy tales manifestaciones son características de sociedades estatales, que ante situaciones de crisis e inminente desprestigio de las clases sacerdotales implementan otros artificios, como el aumento de la población esclava o la sumisión de otros pueblos por medio de las guerras (Choy 1987: 180-181). Si bien es cierto, estas características pueden tener una mayor semejanza con el proceso Moche en la costa norte, la sociedad Lima parece haberse fundamentado sobre la base de un control religioso a partir del trabajo corporativo, pues hasta el momento no existen evidencias concretas de un ejército coercitivo durante esta época.

Pero cuáles son las características de los nuevos grupos emergentes en los centros urbanos de la costa central durante esta época? hasta el momento, sabemos que los nuevos actores en la dinámica social de los centros urbanos tienen características más seculares, y que estas élites debieron estar relacionadas al usufructo de la producción del alfar Nievería. Algunos han postulado que estas vajillas corresponderían a cerámica de prestigio y estarían relacionadas más a grupos de élites locales (Kaulicke 2000: 329), dicho prestigio de la cerámica Nievería se habría iniciado en la época $1 \mathrm{~A}$ y habría permanecido hasta la época 2A del Horizonte Medio (Shady 1982: 21). Por otro lado, sobre la base de hallazgos de contextos funerarios asociados a dicho estilo cerámico se proponen claras diferencias sociales (Patterson 1966; Shady 1982; Kaulicke 2000) las cuales habrían permanecido hasta la época 2A del Horizonte Medio; sin embargo, muchas de las inferencias realizadas se han basado sobre muestras de vasijas cuyos datos de contextos funerarios se encuentran incompletos. Recientemente, el análisis de una muestra de 2,250 fragmentos recuperados de distintos contextos asociados a la arquitectura del Centro Urbano de Pucllana sugieren que el denominado Nievería Temprano estilísticamente se encuentra relacionada en un primer momento a la costa sur y posteriormente al área ayacuchana (Ccencho 2006: 33). Esta advertencia realizada en el alfar Nievería ha sido comprobada en contextos de primer orden, las que se asociaron a actividades rituales de gran importancia (Ríos 2008). En tal sentido, se ha propuesto a modo de hipótesis la presencia de un movimiento político-religioso durante esta época:

Aparentemente, este movimiento originó una crisis en el aparato gubernamental resuelta por una fuerza que tomó el poder, el cual es más flexible a dicho movimiento político religioso sureño, y probablemente estaba de acuerdo con la necesidad de hacer cambios drásticos en la sociedad. (Ccencho 2006: 33)

Finalmente queremos agregar que muchos aspectos de las variaciones estilísticas notadas en la alfarería de la costa central durante la primera época del Horizonte Medio también están ocurriendo en la cerámica de élite de la costa norte. Según Castillo la etapa Moche Tardío es posible diferenciarlo en tres épocas, en la primera época "A" se caracteriza por la ausencia de los motivos Wari, en contraste, existe una popularidad en el desarrollo de cerámica decorada con "líneas finas" y primeras evidencias asociadas a formas de estilo Nievería, en un segundo momento de esta misma época se hace presente cerámica importada Nievería y decoraciones del estilo Chakipampa y Pacheco. El auge y decadencia de diseños "líneas finas" asociados a la 
desaparición de las tumbas en bota (tumbas de élite) han sido considerados como marcadores de la finalización del proceso Moche (Castillo 2000: 173). Por otro lado, en la costa sur también se manifiestan cambios en los patrones de asentamiento, Silverman sugiere que los asentamientos asociados a la fase Nasca 5 (525 d.C.) fue una continuación del patrón de asentamiento Nasca 3 construyéndose varios complejos arquitectónicos cívicos, habitacionales y ceremoniales, mientras que en la siguiente etapa fases 6 y 7 (Horizonte Medio) los asentamientos decrecen considerablemente en el valle de Nasca (Silvermann 1992: 38-40). Fue también durante la fase 5 que se construyeron la mayor cantidad de acueductos en Nasca (Schereiber y Lancho 1988) probablemente como respuesta a las fuertes sequías desarrolladas en toda el área andina (Shimada et al. 1991) asimismo, Roark sostiene que el aumento de temas militaristas en la cerámica Nasca 6 reflejarían la realidad sociopolítica por la que se desarrollaba la sociedad (1965: 56). Es al parecer que durante los 550 a 600 d.C., empiezan las influencias Huari en la región de Nasca estableciéndose posteriormente Pacheco durante el Horizonte Medio 1B (Silvermann 1992: 40).

Desde esta perspectiva, se entiende que la arquitectura definida en la Plataforma IV mantenga ciertas características con la Huaca San Marcos; es decir, la pérdida del carácter ceremonial expresado en la arquitectura. Dichos cambios deben de estar relacionados a grupos emergentes con nuevas cánones probablemente resultado de las interacciones producidas desde la época 7 y de nuevas tendencias de cambio en el orden político - ideológico que se insertaron en la dinámica social Lima.

\section{Conclusiones}

Las excavaciones desarrolladas en la Plataforma IV del Centro Ceremonial de Pucllana nos a permitido realizar algunas comparaciones con otros centros urbanos, la cual nos a llevado ha plantear nuevos aspectos en la dinámica social Lima durante las primeras épocas del Horizonte Medio.

La Plataforma IV en sus fases tardías se desarrolló por Tres Etapas Constructivas donde se evidenciaron varias remodelaciones en los elementos arquitectónicos (muros, banquetas, pisos y postes) conllevando también en algunos casos a cambios en el manejo del espacio en los recintos definidos. La Primera Etapa Constructiva se conformó por una serie de recintos restringidos asociados a una plataforma, la cual debió configurarse como el sector más importante, durante esta etapa las funciones principales desarrolladas corresponden a actividades de características ceremoniales. En la Segunda Etapa Constructiva cambió radicalmente las características del espacio y la función, pues se conformó una gran plaza asociada a postes cuya función principal fue la producción de barro y otras actividades complementarias. Mientras que en la Tercera Etapa Constructiva se conformaron dos componentes diferenciados; una de característica ceremonial y otra pública, los cambios en la orientación del sector más importante y la capacidad de congregación manifiestan una participación compartida de dos componentes sociales diferenciados, probablemente una sacerdotal y otra civil o de características más seculares. En cada una de las etapas constructivas se evidenciaron diversas manifestaciones rituales (quema de algunos recintos, festines ceremoniales a pequeña escala, ofrenda de hoyos pequeños, ofrendas de poste invertido y ofrendas de cerámica) muchos de ellos asociados al proceso de inicio o clausura de una etapa constructiva. Es en la Primera Etapa Constructiva, donde se observó una mayor reminiscencia a las actividades rituales a pesar de que existen ciertas evidencias que indican que tales manifestaciones tuvieron mayor arraigo en etapas anteriores. Por otro lado, en la Segunda Etapa Constructiva la Plataforma IV y V se transformaron en una gran plaza destinada a la producción de barro, este proceso supone que 
los ambientes alrededor de esta plaza debieron ser remodeladas a gran escala. Al parecer, este proceso no duró mucho tiempo y se encuentra alternados con otras actividades que se le ha denominando mantenimiento preventivo de la plaza (Ríos 2008: 287). Este patrón de conducta parece repetirse cada cierto tiempo cuando un espacio de gran importancia culmina con un ciclo de funcionamiento y se plantea cambios drásticos en el patrón arquitectónico (Ríos 2008: 137). Similares casos fueron reportados en el Conjunto Tello de Cajamarquilla (Segura 2001: 167), asimismo las actividades de construcción y destrucción en la Huaca Tupac Amaru "B" también parecen corresponder a este comportamiento (Rodríguez 1999: 66-71) tales eventos están relacionados con el desarrollo de actividades rituales, los que parecen corresponder a patrones cíclicos que Eliade (1967) denomina "Tiempo Sagrado".

Las Tres Etapas Constructivas definidas, de acuerdo a las evidencias recuperadas corresponden a la época 1A del Horizonte Medio, la propuesta de segregación del estilo Nievería Temprano (Ccencho 1996) fue confirmado por arquitectura superpuesta asociadas a fragmentos Nievería con decoraciones foráneas del área ayacuchana. Lo que demostraría que la Tercera Etapa Constructiva corresponde al tránsito de la época $1 \mathrm{~A}$ al 1B del Horizonte Medio y es justamente en estos momentos donde se observan los cambios más drásticos en la arquitectura. Los fragmentos Nievería Temprano recuperados de la Segunda y Tercera Etapa Constructiva se asociaron a fragmentos de cerámica Lima de las fases 7, 8 y 9 sin poder comprobarse que correspondan a una secuencia con valides cronológica tal como las planteó Patterson (1966). Por el contrario, debe de asumirse estas fases como un sólo componente (Montoya 1966; Guerrero y Palacios 1992; Ríos 2008) donde se encuentra coexistiendo con el Nievería Temprano (Ríos op. cit.).
También podemos concluir que no existió ninguna etapa de abandono durante esta época, las fases tardías definidas en la arquitectura manifiestan una ocupación permanente sin ninguna interrupción. Por lo tanto, las alteraciones climáticas de sequias y etapas húmedas que afectaron a todo el área andina (Shimada et al. 1991) fueron simples condicionantes en el proceso de transformaciones sociales que se estaban generando en la cada vez más compleja sociedad Lima. En contraste, se demuestra que el desarrollo arquitectónico no solamente continuó en el centro ceremonial si no también en los sectores públicos de la parte baja del centro urbano durante esta época (Ríos op. cit.).

Por último, se propone que la sociedad Lima había ingresado a una serie de profundas transformaciones sociales e ideológicas, las que probablemente se habrían iniciado desde la época 7 del Período Intermedio Temprano, la desestabilización económica producida durante la época 1A del Horizonte Medio habría sido un condicionante más, el cuestionamiento a las clases sacerdotales debió de incentivarse más durante esta época, ante la poca eficacia de las plegarias a los dioses. En este panorama, surgen nuevos actores en la dinámica social de los centros urbanos de la costa central, pues la pérdida del poder sacerdotal no solamente se expresa en la arquitectura, también parece manifestarse en la reminiscencia permanente de actividades rituales posiblemente como últimos artíficos para mantener el control de la población. Los nuevos actores sociales al parecer son grupos de élites con características seculares o civiles, hipotéticamente pensamos debieron corresponder a grupos dedicados a las transacciones comerciales a largas distancias, pues estos constantemente debieron estar relacionados a las innovaciones tecnológicas e ideológicas que se estaban desarrollando en otras sociedades contemporáneas (Moche, Nasca, Recuay, etc.); además de otras organizaciones sociales 
ubicadas en las estribaciones andinas cercanas a la costa. En tal sentido, las nuevas influencias sureñas que se manifiestan en el Alfar Nievería Temprano posiblemente correspondan a resultados de alianzas estratégicas entre los nuevos grupos emergentes, las nuevas normas establecidas por estos, debieron trascender a los niveles superestructurales, es decir la búsqueda de nuevas deidades tutelares que satisfacieran las fuertes tradiciones religiosas de los poblaciones al servicio de los centros ceremoniales. Estos parecen llegar a su fin cuando nuevos grupos de las zonas altoandinas irrumpen en el desarrollo social de la costa central, los nuevos rasgos iconográficos en el Alfar Nievería manifiestan un alto grado de influencia de los andes ayacuchanos, al parecer un movimiento de fuertes connotaciones religiosas (Menzel 1968: 185-186) con características imperiales (ibid.: 189) fue el responsable de los profundos cambios de la sociedad no solamente en la costa central sino a nivel pan-andina; lo que originó el abandono del centro ceremonial de Pucllana.

\section{REFERENCIAS BIBLIOGRÁFICAS}

Alarcón, Pedro

1971 Tres fases técnico constructivas de la Huaca San Marcos. (Tesis para optar el Grado de Bachiller en Arqueología), Universidad Nacional Mayor de San Marcos, Lima.

Castillo, Luis

2000 "La presencia de Huari en San José de Moro". Boletín de arqueología PUCP, Huari y Tiwanaku: Modelos vs. Evidencias. Primera parte (Peter Kaulicke y William H. Isbell eds), 04, pp. 143180, Pontificia Universidad Católica del Perú, Lima.

Castillo, Luis y Christopher Donnan

1994 La ocupación Moche en San José de Moro Jequetepeque Moche. Propuestas y perspectivas. Travaux de I'Institut Francais d'Estudes Andines 79, pp. 93-146, Lima.
Cavatrunci, Claudio

1999 "Cajamarquilla, un centro urbano de la costa central". En Inca Perú 3000 años de Historia, pp. 353-363. Madrid.

Ccencho, José

1999 "Alfarería Pucllana: Propuesta de una metodología de clasificación y algunos aportes para el entendimiento de la Cultura Lima”. En XII Congreso del Hombre y la Cultura Andina, Tomo II, pp. 140-150, Universidad Nacional San Cristóbal de Huamanga, Ayacucho.

2006 "El Alfar Pucllana Nievería. Cambios registrados en una vajilla ceremonial y sus implicancias sociales". Cuadernos de Investigación/ INC 1, pp. 17-34, Lima.

Choy, Emilio

1987 "La revolución neolítica y los orígenes de la civilización Peruana". Antropología e Historia, Tomo1, pp. 122-195, Lima.

Eliade, Mircea

1967 Lo sagrado y lo profano, Guadarrama, Madrid.

Fernández, José

1960 "El Estilo Maranga. Apuntes preliminares para el estudio y clasificación". Antiguo Perú. Espacio y Tiempo, pp. 241-250, Lima.

Flores, Isabel

1981 "Investigaciones arqueológicas en la Huaca Juliana. Miraflores". Boletín de Lima 13, pp. 65-70, Lima.

2005 Pucllana: esplendor de la Cultura Lima. Instituto Nacional de Cultura (INC), Lima.

2007 Informe final de las excavaciones del Proyecto Arqueológico Huaca Pucllana Temporada 2006, Informe presentado al Instituto Nacional de Cultura. 
Franco, Régulo y Ponciano Paredes

2000 "Templo Viejo de Pachacamac: Nuevos aportes al estudio del Horizonte Medio". Boletín de Arqueología PUCP, Huari y Tiwanaku: Modelos vs. Evidencias. Primera parte (Peter Kaulicke y William H. Isbell eds), № 04, pp. 607-630, Pontificia Universidad Católica del Perú, Lima.

2003 El Templo Viejo de Pachacamac. Estudios Arqueológicos (1986-1990), Archivo en PDF, Trujillo.

Guerrero, Daniel y Jonathan Palacios

1994 "El surgimiento del estilo Nievería en el valle del Rímac". Boletín de Lima 9, pp. 275-311, Lima.

Jijón y Caamaño, Jacinto

1949 Maranga contribución al conocimiento de los aborígenes del valle del Rímac, Perú. La Prensa Católica, Quito.

Kaulicke, Peter

2000 "La sombra de Pachacamac: Huari en la costa central". Boletín de Arqueología PUCP Huari y Tiwanaku: Modelos vs. Evidencias. Primera parte (Peter Kaulicke \& William Isbell eds.) № 04, pp. 597-605, Pontificia Universidad Católica del Perú, Lima.

Kroeber, Alfred

1954 "Proto Lima and A Middle Period Culture of Peru”. Fieldiana Anthropology 1, pp. 1-115, Natural History Museum, Chicago.

Lavallée, Daniélle

1966 "Una colección de cerámica de Pachacamac: Estudio Morfológico y estilístico". Revista del Museo Nacional, T. XXXIV, pp. 220-246, Lima.

MacNeisch, Richard; Tomas Patterson and David Browman

1975 "The Central Peruvian Prehistoric Interaction Sphere". Papers of the Roberts S. Peabody Foundation of Archaeology 7, Massachusetts.
Menzel, Dorothy

1968 La Cultura Huari. Las Grandes civilizaciones del Antiguo Perú. Tomo VI, Compañía de Seguros y Reaseguros Peruano-Suiza, Lima.

Mogrovejo, Juan

1999 "Cajamarquilla y el fin de la Cultura Lima”. Boletín del Instituto Riva Agüero 26, pp 227-243, Lima.

Montoya, Huayta

1995 Análisis de fragmentería cerámica excavada en un relleno de clausura en el Complejo Arqueológico Huaca Pucllana. (Tesis para optar el título de licenciada en Arqueología), Pontificia Universidad Católica del Perú, Lima.

Narváez, Joaquín

2000 "Dos mates pirograbados de la Época 2 del Horizonte Medio de la Huaca San Marcos". Boletín del Museo de Arqueología y Antropología 2, pp. 8-15, Lima.

2006 Sociedades de la antigua ciudad de Cajamarquilla. Investigaciones arqueológicas en el Sector XI del Conjunto Tello y un estudio de la colección tardía del Conjunto Sestieri. Ediciones Avqui, Lima.

Palacios, Jonathan y Daniel Guerrero

1992 "Potrero Tenorio. Un enterramiento ritual de ofrenda del estilo Nievería en el valle del Rímac". Pachacamac 1, pp. 75-100, Lima.

Paredes, Juan

2000 "La Cultura Lima en el valle bajo del río Chillón”. Arqueología y Sociedad 13, pp. 133-158, Lima.

Patterson, Thomas

1966 "Pattern and process in the Early Intermediate Period Pottery of the Central Coast of Peru". University of California Publications I Anthropology 3, Berkeley - Los Angeles. 
Quilter, Jeffrey

1986 "Cerro Media Luna; an Early Intermediate Period site in the Chillon Valley, Peru". Nawpa Pacha 24, pp. 73-98, Berkeley California.

Ríos, Nilton

2007 "Tres etapas constructivas en la Plataforma IV de la Huaca Pucllana”. Ponencia presentada al XV Congreso del Hombre y la Cultura Andina y Amazónica, Universidad Católica de Santa María, Arequipa.

2008 Restos de actividades rituales en la segunda etapa constructiva de una plaza Lima Tardio: un caso en Pucllana. (Tesis presentada para optar el Título de Licenciado en Arqueología). UNMSM, Lima.

Roark, Richard

1965 "From Monumental to Proliferous in Nasca Pottery". Nawpa Pacha 3, pp. 1-92, Berkeley California

Rodríguez, Aurelio

1999 Excavaciones en Huaca Tupac Amaru B. Un complejo de arquitectura monumental de la cultura Lima, del valle del Rímac, costa central del Perú. (Tesis de la Facultad de Letras y Ciencias $\mathrm{Hu}$ manas especialidad de Arqueología), Pontificia Universidad Católica del Perú, Lima.

Schereiber, Katharina y Josue Lancho

1988 "Los puquios de Nasca: Un sistema de galerías filtrantes”. Boletín de Lima 59, pp.51-62, Lima.

Segura, Rafael

2001 Rito y economía en Cajamarquilla. Investigaciones arqueológicas en el Conjunto Julio C. Tello. Fondo Editorial de la Pontifica Universidad Católica del Perú, Lima.

Shady, Ruth

1982 "La Cultura Nievería y la interacción social en el mundo andino de la época Huari”. Arqueológicas 19, pp. 5-108, Lima.
Shimada, Izumi, Cristal Chaaf, Lonie G. Thompson, Ellen M. Thompson y R. Bird

1991 "Implicancias en los andes de una gran sequía del siglo VI dC., en los Andes Peruanos". Boletín de Lima 77, pp. 33-56. Lima.

Silva, Jorge

1996 Prehistoric Settlement Patterns in The Chillon River Valley, Peru. Ph. D. Dissertation, Department of Anthropology, University of Michigan, Ann Arbor, Michigan.

1992 "Ocupaciones postformativas en el valle del Rímac: Huachipa - Jicamarca”. Pachacamac 1, pp. 49-74

Silvermann, Helaine

1992 "Estudio de los patrones de asentamientos y reconstrucción de la antigua sociedad Nasca”. Boletín de Lima 82, pp. 33-44, Lima.

Tabío, Ernesto

1965 Excavaciones en la Costa Central del Perú (1955-1958). Academia de Ciencias Departamento de Antropología, La Habana.

Uhle, Max

1998 "Acerca de las culturas tempranas de Lima y sus alrededores (1910)". En Max Uhle y el Perú Antiguo, (Kaulicke ed.), Lima Pontificia Universidad Católica del Perú, pp. 231-254, Lima.

\section{Agradecimientos}

Deseamos agradecer a la doctora Isabel Flores, directora del Proyecto Huaca Pucllana, por permitirnos hacer uso de los datos obtenidos en los trabajos de excavación. Asimismo, a varios compañeros del proyecto incluyendo a los obreros que con su esfuerzo y dedicación hicieron posible que las excavaciones se desarrollaran adecuadamente. 